\title{
Volumetric, planar and linear airway comparison after maxillomandibular advancement surgery
}

\author{
Deepa Vyas \\ West Virginia University
}

Follow this and additional works at: https://researchrepository.wvu.edu/etd

\section{Recommended Citation}

Vyas, Deepa, "Volumetric, planar and linear airway comparison after maxillomandibular advancement surgery" (2014). Graduate Theses, Dissertations, and Problem Reports. 571.

https://researchrepository.wvu.edu/etd/571

This Thesis is protected by copyright and/or related rights. It has been brought to you by the The Research Repository @ WVU with permission from the rights-holder(s). You are free to use this Thesis in any way that is permitted by the copyright and related rights legislation that applies to your use. For other uses you must obtain permission from the rights-holder(s) directly, unless additional rights are indicated by a Creative Commons license in the record and/ or on the work itself. This Thesis has been accepted for inclusion in WVU Graduate Theses, Dissertations, and Problem Reports collection by an authorized administrator of The Research Repository @ WVU. For more information, please contact researchrepository@mail.wvu.edu. 


\title{
Volumetric, Planar and Linear Airway Comparison after Maxillomandibular Advancement Surgery
}

\author{
Deepa Vyas, D.M.D.
}

\section{A THESIS}

Submitted to:

The School of Dentistry at West Virginia University

In partial fulfillment to the requirements

for the degree of

Master of Science In Orthodontics

\author{
Peter Ngan, D.M.D., Chair \\ Chris Martin, D.D.S., M.S. \\ Bryan Weaver, D.D.S., M.D. \\ West Virginia University \\ Department of Orthodontics
}
Morgantown, West Virginia
2014

Keywords: maxillomandibular advancement, sleep apnea, cbct Copyright 2014 Deepa Vyas 


\title{
ABSTRACT \\ Volumetric, Planar and Linear Airway Comparison After Maxillomandibular Advancement Surgery
}

\author{
Deepa Vyas, D.M.D., Peter Ngan, D.M.D., Chris Martin, D.D.S., M.S., Bryan Weaver, D.D.S., \\ M.D., Mary E.Burns D.M.D. and Erdogan Gunel, Ph.D.
}

Background and Objectives: Treatment of sleep apnea can be accomplished using both non-surgical and surgical methods. Surgical treatment is further classified into phase I and II surgery. When phase I treatment fails, orthognathic surgery is judged to be the subsequent step in treating these patients. Orthognathic surgery is considered phase II treatment and can consist of a maxillomandibular advancement (MMA) ${ }^{1-11}$. Until recently, most of the data gathered on patients how have had a maxillomandibular advancement has been completed using lateral cephalograms. The rationale for this study is to gain a better understanding of the alteration in linear, planar and volumetric posterior airway space following double-jaw advancement surgery with a counter-clockwise rotation of the occlusal plane.

Methods: A total of 28 subjects pre- and post-surgical CBCT scans were evaluated. All of the individuals underwent a maxillomandibular advancement with a counterclockwise rotation of the occlusal plane. All DICOM files were analyzed using Dolphin 3D Imaging 11.5, licensed to West Virginia University Department of Orthodontics. The CBCT volume was used to create right lateral cephalograms which were then used for linear cephalometric measurements. The 3D volume was also utilized to find cross-sectional measurements from axial slices taken from the cone-beam images at specific points: PNS, CV1, CV2 and CV3. Finally, CBCT images were used to find volume measurements at explicit regions along the posterior airway space. Data was analyzed using a matched-pair test.

Results: When all subjects were grouped together the p-value for the change in all variables was $<0.05$. This indicates that there was a statistically significant change in all variables regardless of the method used to evaluate pre- and post-surgery changes. It also suggests that although CBCT is a valuable tool to evaluate airway change, cephalometric radiographs can be used to determine whether change in PAS is significant when it pertains to maxillomandibular advancement surgery.

Conclusions: The maxillomandibular advancement procedure with or without genioplasty illustrated great increases in posterior airway space in both 2-dimensional and 3-dimensional analyses. However, more information was available in regards to site of airway obstruction when utilizing the $3 \mathrm{D}$ data in comparison to $2 \mathrm{D}$. Patients with obstructive sleep apnea should be presented with the option of MMA surgery as a treatment option if CPAP is not tolerated or other therapies have failed. 


\section{DEDICATIONS}

To my husband and best friend, Brandon Kiger. Thank you for being my rock during stressful times. Your knowledge, organizational skills and upbeat attitude are what kept me afloat when I was overwhelmed with worry. I'm so glad we have the rest of our lives to support each other.

To my parents, Rekha and Kirit Vyas, who supported me through any education endeavor I set out to pursue. Your unconditional love and encouragement kept me going when I was far away from home. I hope that I can be as great parents as the both of you.

To my orthodontic “wife" Nicole DeShon. I couldn't have completed the program without your friendship. We've made memories that will last us a lifetime. Although we will be living far from each other, I know we will still keep in touch.

To my sister and brother, Charul and Pranav Vyas. Thanks for all the fights, laughs and love. I think I'm ready to be "grown up" like you guys. I love you both. 


\section{ACKOWLEDGEMENTS}

There are a number of people without whom this thesis might not have been written, and to whom I am greatly indebted. I would like to take this opportunity to thank not only the individuals who have contributed to my thesis, but also those who have assisted me throughout my specialty training.

Dr. Peter Ngan, for being the chairman of my thesis committee, for your countless hours of dedication to this program, and for your endless commitment to me both personally and professionally. You have been a mentor, educator, and friend. You have believed in me since the onset of my career and I am truly indebted. Your heart is full of love and support and I thank you.

Dr. Chris Martin, for being a member of my thesis committee, for being a full-time adviser, and for guiding me through my educational journey. I have learned an innumerable amount of knowledge from you, all the while making me laugh on a daily basis. I thank you.

Dr. Bryan Weaver, for being a member of my thesis committee and guiding me throughout this process. I thank you.

Dr. Mary E. Burns, for your contribution of CBCT scans of subjects utilized throughout this research project and for your continued dedication and drive to produce evidenced based studies. I thank you.

Dr. Erdogen Gunel, for your time and effort in preparing and interpreting the statistical analyses conducted throughout this project. I thank you.

Drs. Glenn Boyles, Scott Little, Dan Foley, Jeff Gilmore, Mike Hazey, Tom Jarrett, Kerry Kirsch, Ned McFarland, Rajia Sebbahi, Lew Wright and Tim Tremont, for your time and enthusiasm granted to this program. You are great examples of our young orthodontic profession and set a standard in which to aspire. I am thankful that I was given the opportunity to learn from you. Each of you have gifted me a different piece of knowledge in preparing me for the unbelievable journey that I am about to embark. Without hesitation, I thank you. 
Karen Pacilli, Sandy Cooke, and Leona Wolfe, for your support and special assistance offered in clinic. You are an asset and I am so grateful to have gotten the opportunity to work with you. I thank you.

Sheri Whitacre and Carrie Trejo, for your organizational support and assistance with patient scheduling. You are an asset and I am so grateful to have gotten the opportunity to work with you. I thank you.

Nicole DeShon and Lance Pittman - my fellow classmates, for your support you have shown me throughout our time here at West Virginia University. Good luck to each of you in your future endeavors and I thank you.

\section{Ronnie Sparks, Jung Mee Kim, Holly Eppard, Alice Wang, Doyoung Choi and Chad}

Westfall - my former fellow residents, for being great leaders, role models, and teachers. Most importantly, however, were the friendships we developed throughout the course of this residency. The previous two years were quite an experience and you all made it one of the most memorable times of my life. I miss all of you and I thank you.

Nick, Jen, Travis, Jason, Tim and Martin - my fellow residents, for being insightful, giving, and willing to listen when I needed it most. Like the previous residents listed above, we too have sparked friendships that I know will be everlasting. Good luck to each of you in your future endeavors and I thank you. 


\section{TABLE OF CONTENTS}

ABSTRACT..........................................................................

DEDICATIONS.........................................................II

ACKNOWLEDGEMENTS................................................IV

TABLE OF CONTENTS....................................................VI

LIST OF TABLES.........................................................IX

LIST OF FIGURES.......................................................

CHAPTER 1: INTRODUCTION............................................1

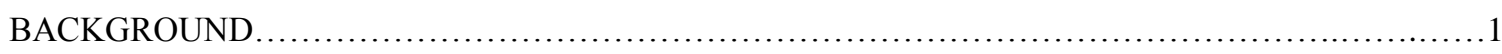

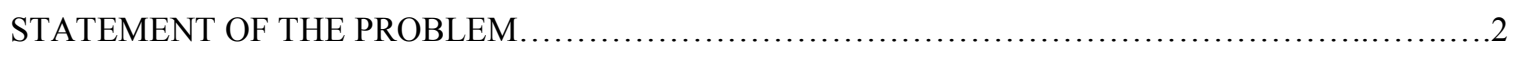

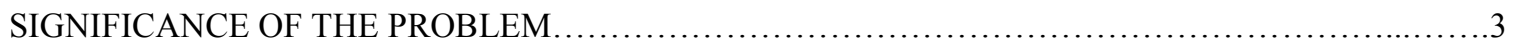

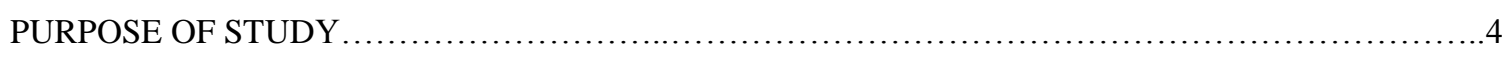

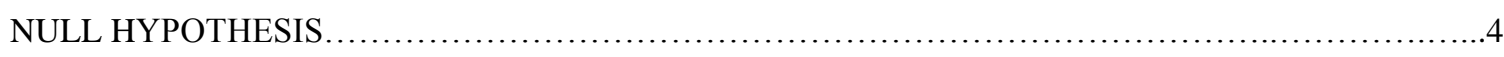

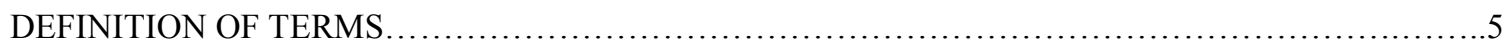

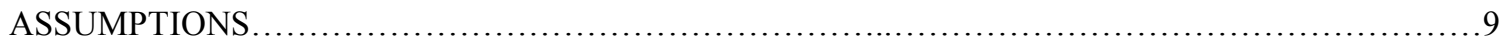

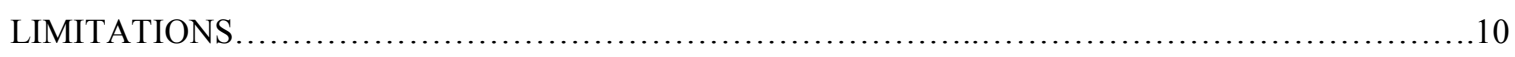

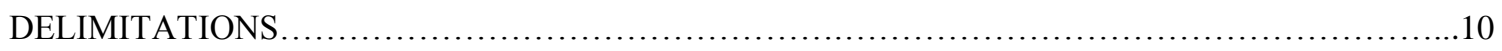

CHAPTER 2: REVIEW OF LITERATURE...........................11

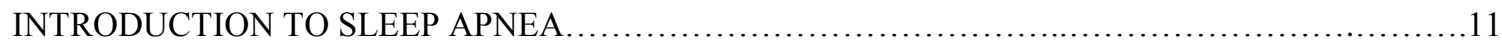

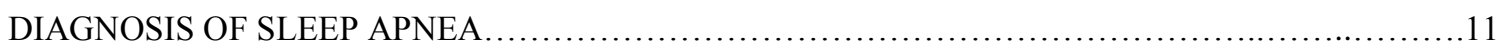

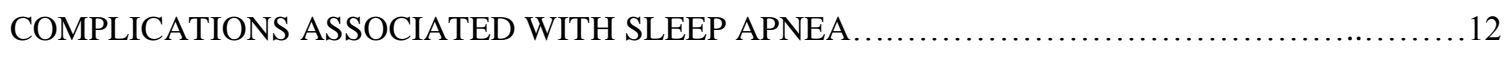

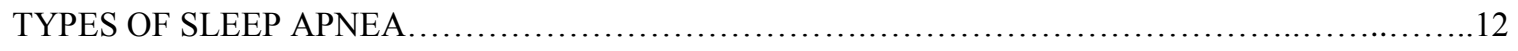

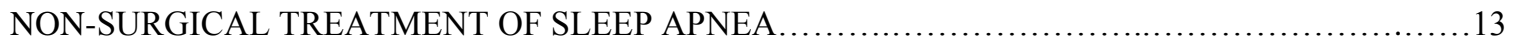

SURGICAL TREATMENT FOR SLEEP APNEA..............................................

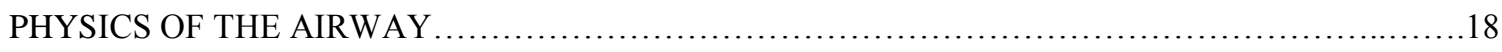


TRADITIONAL CEPHALOMETRIC AIRWAY ANALYSIS ....................................... 19

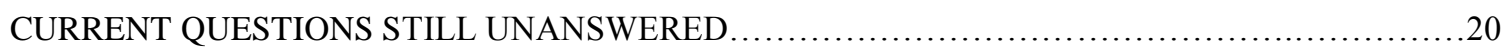

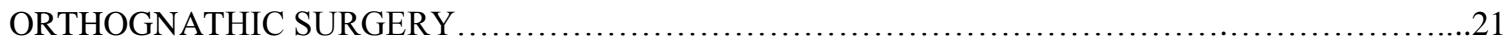

AIRWAY CHANGES WITH CLASS III CORRECTION ............................................21

AIRWAY CHANGES WITH MANDIBULAR ADVANCEMENT ALONE.............................21

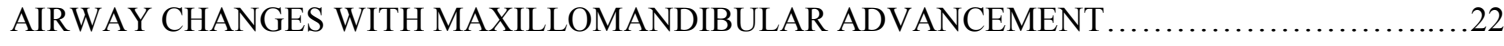

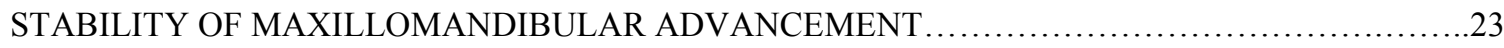

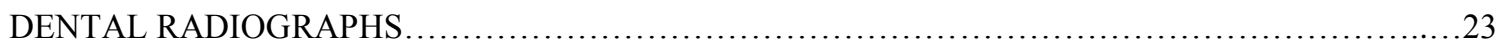

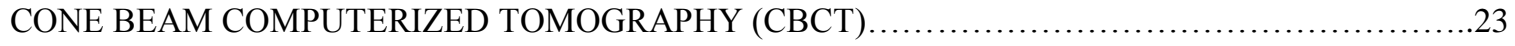

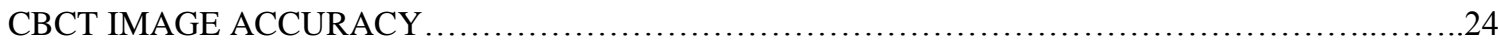

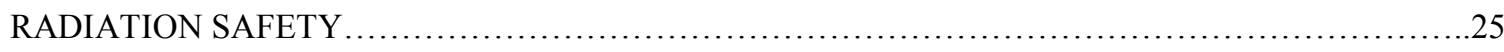

CBCT BENEFITS, LIMITATIONS, AND APPLICATIONS WITHIN ORTHODONTICS...............26

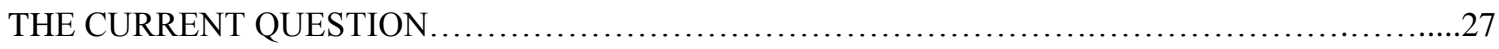

CHAPTER 3: EXPERIMENTAL DESIGN AND METHODS................28

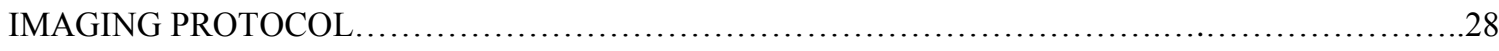

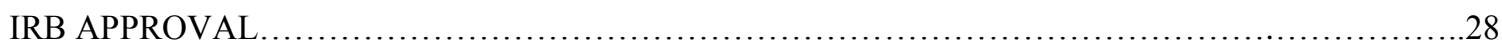

METHODOLOGY

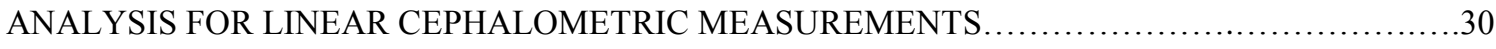

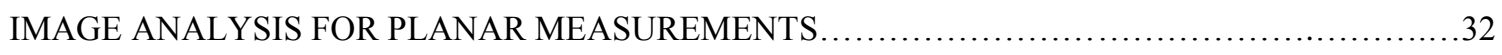

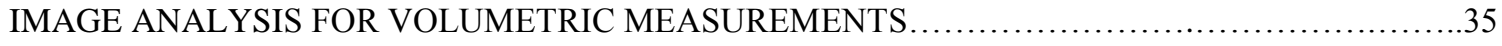

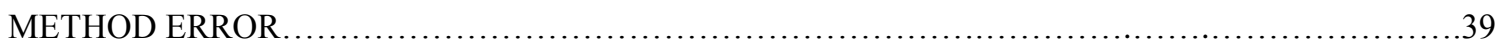

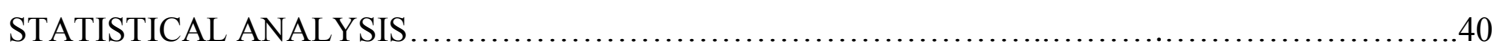

CHAPTER 4: RESULTS.................................................40

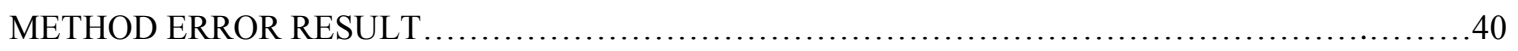

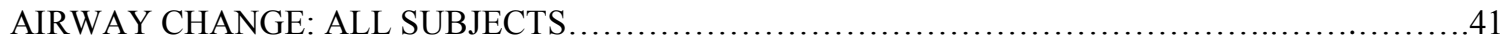

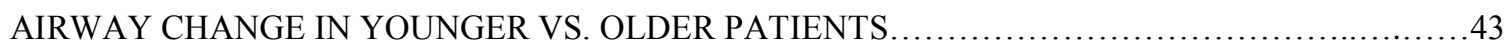

CHANGES IN AIRWAY BY MMA WITH OR WITHOUT GENIOPLASTY ..........................46 


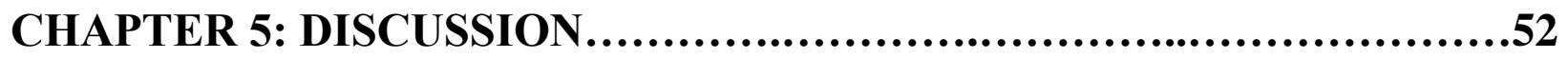

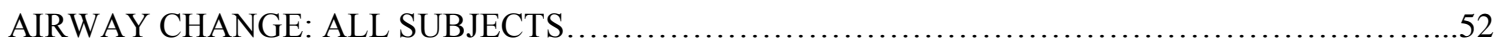
AIRWAY CHANGE IN YOUNGER VS. OLDER SUBJECTS $\ldots \ldots \ldots \ldots \ldots \ldots \ldots \ldots \ldots \ldots \ldots \ldots \ldots \ldots . \ldots \ldots$ CHANGES IN AIRWAY IN GROUPS WITH OR WITHOUT GENIOPLASTY ....................53

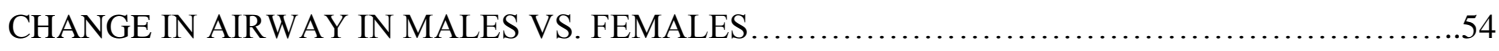

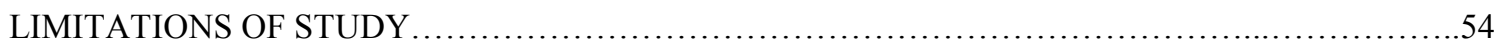

CHAPTER 6: SUMMARY AND CONCLUSIONS.........................55

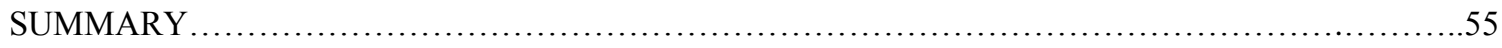

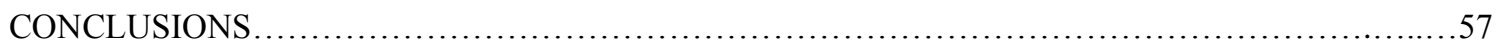

CHAPTER 7: RECOMMENDATIONS FOR FUTURE RESEARCH........57

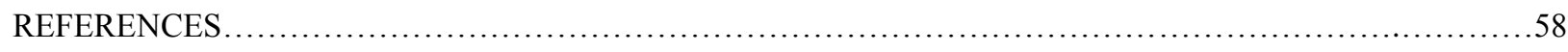

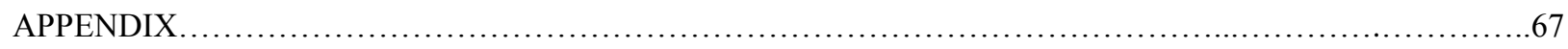

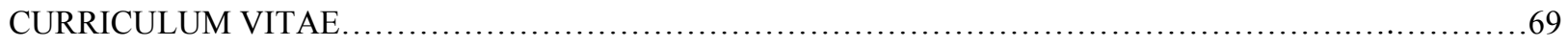




\section{LIST OF TABLES}

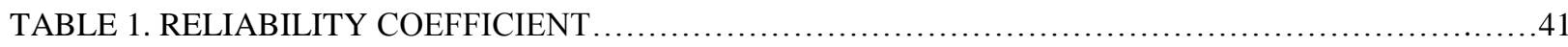

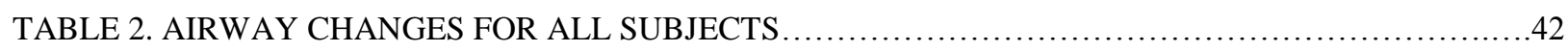

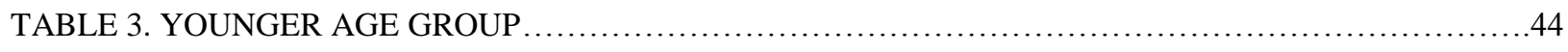

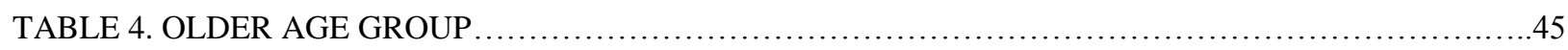

TABLE 5. SUBJECTS WITH MMA WITHOUT GENIOPLASTY ..................................... 47

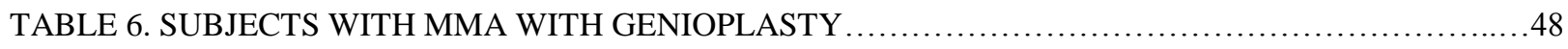

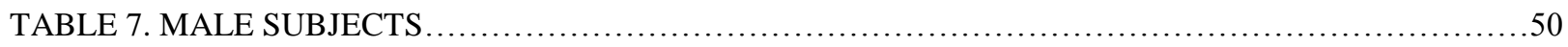

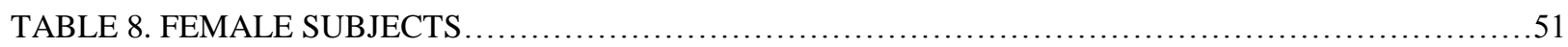




\section{LIST OF FIGURES}

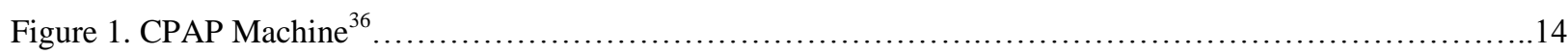

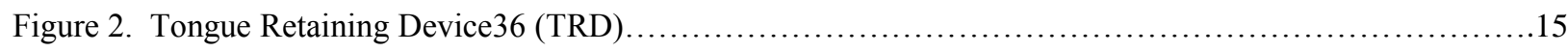

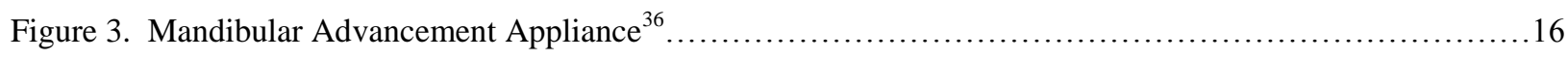

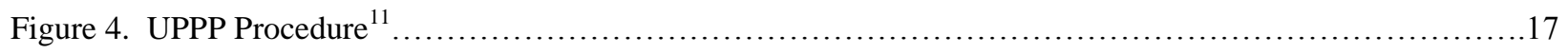

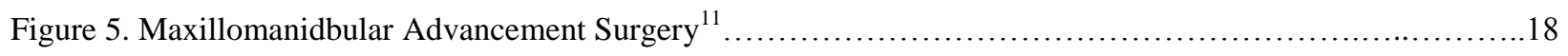

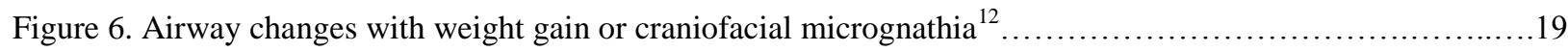

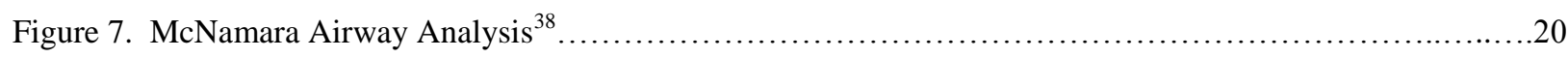

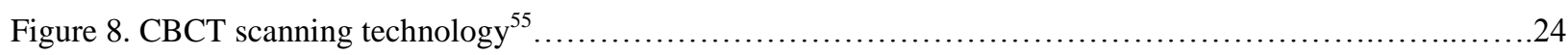

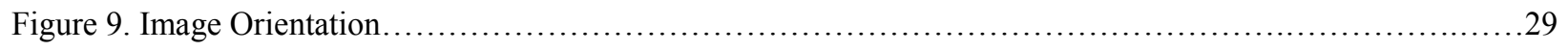

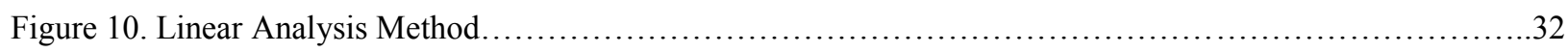

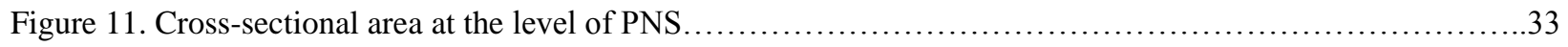

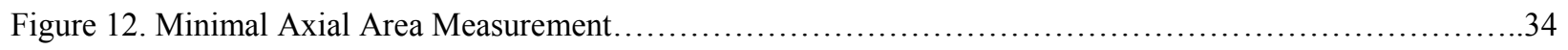

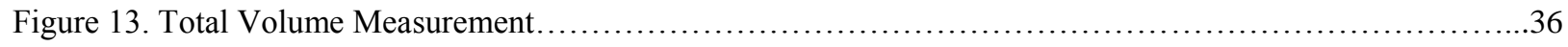

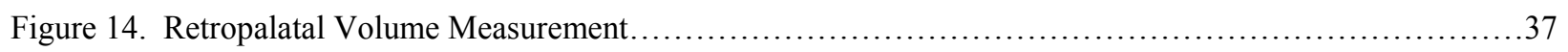

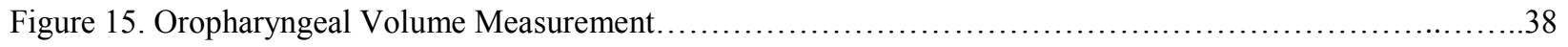

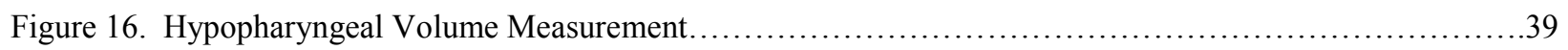




\section{CHAPTER 1: INTRODUCTION}

\section{Background}

The official definition of obstructive sleep apnea according to the American Academy of Sleep Medicine is as follows: recurrent episodes of partial or complete upper airway obstruction during sleep despite ongoing inspiratory effort ${ }^{12}$.

According to the United States Department of Health, more than 12 million people are affected by obstructive sleep apnea and many more individuals go undiagnosed. In fact, 1 in 5 adults have a form of mild sleep apnea; while 1 in 15 have moderate severity OSA. According to the Wisconsin cohort study, $93 \%$ of women and $82 \%$ of men have undiagnosed moderate to severe sleep apnea $^{13}$. Sleep apnea can affect all age ranges from children to adults ${ }^{12}$. It has been documented that 3.2 to $12.1 \%$ of children habitually snore and anywhere from 0.3 to $10.3 \%$ have some form of $\mathrm{OSA}^{4,14}$.

In adults, the symptoms that are often seen in relation of obstructive sleep apnea are the following: excessive daytime sleepiness (EDS), morning headaches, dry mouth, sore throat, snoring, gastroesophageal reflux, and sexual dysfunction. Excessive daytime sleepiness has been shown to cause an increase in motor vehicle accidents ${ }^{1,2,5,13,15}$. In children, OSA manifests as behavioral problems that are many times misdiagnosed as attention deficit hyperactivity disorder $(\mathrm{ADHD})^{14}$. The importance of identification and treatment of this syndrome for both children and adults is of major concern, since if OSA is left untreated it can lead to severe complications in a person's overall health ${ }^{2,3,12,14-16}$. 
Treatment of sleep apnea can be accomplished using both intraoral and extraoral appliances as well as surgery. The gold standard to treat sleep apnea is through the use of a continuous positive airway pressure (CPAP) machine ${ }^{12}$. The CPAP machine works by using air pressure creased by the device to open the airway during sleep, thus preventing collapse $\mathrm{s}^{3,4,12}$. Although this machine is very effective in treating patients with sleep apnea, it often has unwanted side effects and therefore compliance is low. Mild to moderate forms of sleep apnea can be treated by dental professionals by using devices which can open the airway by either protruding the mandible or repositioning the tongue in a more forward position ${ }^{5,12,14,15}$.

When non-surgical approaches are not tolerated well by patients, a surgical approach to clear the obstruction is warranted. The most common surgical approaches include, but are not limited to: nasal reconstruction, uvulopalatopharyngealplasty (UPPP), or orthognathic surgery ${ }^{3}$. Nasal reconstruction and UPPP surgical approaches are referred to as phase I surgical treatment, but are often times not successful in management of OSA. When phase I treatment fails, orthognathic surgery is judged to be the subsequent step in treating these patients. Orthognathic surgery is considered phase II treatment and can consist of a maxillomandibular advancement $(\mathrm{MMA})^{1-11}$.

\section{Statement of the Problem}

Until recently, most of the data gathered on patients how have had a maxillomandibular advancement has been completed using lateral cephalograms. Although this tool is useful in identifying pharyngeal airway space (PAS) and possible pathologies, it is only a 2-dimensional representation of a 3-dimensional structure. Often times, an image of the PAS seen on a lateral 
cephalogram can underestimate the true obstruction, since it would not represent the true volumetric airway of a given subject ${ }^{17,18}$. However, a relatively new imaging technology that is able to capture 3-dimensional images has become commercially available on the market ${ }^{18}$. This new technology is known as cone-beam computed tomography (CBCT). CBCT offers dental professionals an opportunity to evaluate a patient's airway in 3-dimensions while only exposing them to a minimum about of radiation when compared to other medical CTs. This form of radiography has been documented to reliably provide an accurate representation of volumetric airway dimensions in an efficient manner that is considered superior to images obtained from cephalograms alone $e^{17-21}$. This study will determine if there is a correlation in the reliability of airway measurements using both lateral cephalograms and CBCT images obtained both before and after maxillomandibular advancement surgery.

\section{Significance of Problem}

While CBCT is the preferred method for evaluating pharyngeal airway space, there has not been extensive research published using this technology when compared to research of PAS utilizing lateral cephalograms ${ }^{18}$. Even less research is available in the area of 3-dimensional airway analysis following orthognathic surgery. Therefore, more information, from a 3-dimensional perspective is needed to understand the effects of maxillomandibular advancement. Determining which segment of the airway is most affected by MMA surgery can help in determining if a patient's sleep apnea can be alleviated by surgery or if perhaps another method of treatment may be more appropriate. 


\section{Purpose of Study}

The rationale for this study is to gain a better understanding of the alteration in linear, planar and volumetric posterior airway space following double-jaw advancement surgery with a counter-clockwise rotation of the occlusal plane. In addition, this study will investigate whether there is a correlation between 2-dimensional cephalometric and 3-dimensional cross-sectional measurements at specific sites along the airway. According to Abramson et al., "an association between 3D upper airway anatomy and the presence and severity of OSA has been reported ${ }^{22}$. It is well known that MMA surgery decreases airway resistance and increases airway

patency $^{2,4,8,11,16,22-34}$. However, the specific region of the airway that shows the most increase post maxillomandibular advancement surgery has yet to be distinguished. Therefore, this study will aim to identify which segment of the airway increases the most after MMA surgery. These findings will help to identify which group of individuals will benefit the most from phase II surgery dependent on where their region of most constriction occurs.

\section{Null Hypothesis}

1. There is no significant difference in total airway volume before and after maxillomandibular surgery.

2. There is no significant difference in airway volume before and after maxillomandibular advancement surgery in the retropalatal region

3. There is no significant difference in airway volume before and after maxillomandibular advancement surgery in the oropharyngeal region. 
4. There is no significant difference in airway volume before and after maxillomandibular advancement surgery in the hypopharyngeal region.

5. There is no significant difference in cross-sectional area before and after maxillomandibular advancement surgery at the level of the posterior nasal spine (PNS).

6. There is no significant difference in cross-sectional area before and after maxillomandibular advancement surgery at the level of the $1^{\text {st }}$ cervical vertebra (CV1).

7. There is no significant difference in cross-sectional area before and after maxillomandibular advancement surgery at the level of the $2^{\text {nd }}$ cervical vertebra (CV2).

8. There is no significant difference in cross-sectional area before and after maxillomandibular advancement surgery at the level of the $3^{\text {rd }}$ cervical vertebra (CV3).

9. There is no correlation between cephalometric linear measurements and 3dimensional cross-sectional measurements.

\section{Definition of Terms}

- 2D - Two Dimensional (2-Dimensional)

- Refers to objects that have dimensions of height and width, but do not have depth. Two dimensional objects such as radiographs can be evaluated according to 
height and width, but do not provide an accurate representation of 3-dimensional structures with have a transverse dimension as well.

- 3D - Three Dimensional (3-Dimensional)

○ Refers to objects that have dimensions of height, width and depth. Three dimensional objects better represent actual anatomic structures as long as there is a 1 to 1 ratio.

- Central Sleep Apnea

A type of sleep disordered breathing (SDB), in which there is no obstruction of the airway, but rather a lack of respiratory effort due to failure of the brain to signal muscles that are involved in breathing ${ }^{12}$.

- Cephalogram

○ Synonym for cephalometric radiograph

- Cephalometric Analysis

- A series of measurements based on a radiograph of the head (cephalogram), to determine facial morphology and distinguish dental and skeletal characteristics which are usually compared to norms.

- Cephalometric Radiograph

- A radiograph of the head and neck that is a 2-dimensional representation of these structures.

- Computed tomography (CT)

- A series of radiographs (flat, two-dimensional grayscale images) that are analyzed and rendered via computer to produce a three-dimensional volumetric or surface mapped image. 
- Cone Beam Computed Tomography (CBCT)

- A computed tomography scan utilizing an x-ray beam in the shape of a cone to provide images of bony structures. Data is captured by a flat receiver that detects pulses of cone shaped beam radiation. The result is a stack of two-dimensional grayscale images of the anatomy which can be rendered into volumetric data to visualize anatomical structures in three dimensions. Also known as Cone Beam Volumetric Tomography (CBVT)

- Digital Imaging and Communications in Medicine (DICOM)

- DICOM is a standard for handling, storing, printing, and transmitting medical images. It includes a file format in which data from volumetric radiographs are stored.

- Frankfort Horizontal Plane

- A horizontal plane represented in profile by a line between the lowest point on the margin of the orbit and the highest point on the margin of the auditory meatus.

- Landmark

- A fixed, reproducible (anatomical) point of reference on a radiograph.

- Nasopharynx

- The uppermost portion of the airway, mainly the nose. It begins with the nares, where air enters the nose, and extends back to the hard palate at the superior portion of the soft palate. This includes the nasal septum and the nasal turbinates.

- Obstructive Sleep Apnea

- A sleep disorder that occurs when a person's breathing is interrupted during sleep. It is caused by a narrowing or blocking of the airway due to the collapse of soft 
tissues in the pharynx and retraction of the genioglossus muscle allowing the tongue to slide further posterior than normal, thus blocking the airway.

- Oropharynx

- Includes the oral cavity, beginning with the back portion of the mouth and extending rearward to the base of the tongue. This segment of the posterior pharyngeal wall includes the tonsils. In this area are many muscles, both extrinsic and intrinsic, that control tongue posture: genioglossus, palatoglossus, and the superior longitudinal and transverse muscles of the tongue as examples.

- Referent

- A variable, reproducible (anatomical) point related to a landmark on a radiograph.

- Resolution

- The smallest distance between two points at which the viewer can still distinguish the two points as separate entities. Higher resolutions provide finer detail.

- $\quad$ Sievert (Sv)

- Standard international (SI) unit of radiation dose equivalent. This unit of measure reflects the biological effects of radiation (as opposed to the physical aspects which are characterized by absorbed dose measured in Grays).

- Tomogram

$\circ$ A radiograph representing a "slice" or sectioned focal area by moving an x-ray source and the film in opposite directions during exposure. Structures in the focal plane appear sharp, while structures in front of and behind the plane are blurred.

- Velopharynx 
Extends from the hard palate to the inferior tip of the soft palate. Includes the uvula and the uppermost segment of the posterior pharyngeal wall. Major muscles include the tensor pallatini and levator pallatini, which elevate the soft palate, and the musculous uvulae providing elevation of the uvula.

- Volumetric

- Visual representation of an image in three dimensional space.

- Voxel

- The smallest element in building a three-dimensional image. It is similar to a "pixel" in a flat two-dimensional image display. Voxel size is important in defining the resolution of a volumetric image ( smaller voxel size $=$ higher resolution). The voxel size of a CBCT image can be as small as 0.16 cubic millimeters while the voxel size of a traditional CT image is 0.32 cubic millimeters.

\section{Assumptions}

1. Airway parameters can be accurately and reliably identified using Cone-Beam Computed Tomograph (CBCT) technology.

2. CBCT scans on subjects are taken in centric relation as opposed to centric occlusion.

3. The CBCT scans are of sufficient quality without patient movement introducing artifacts in the scan.

4. The operator has sufficient knowledge of measurement software which is Dolphin 3D version 11.5. 


\section{Limitations}

1. There are differences in medical history, gender, and ethnicity among the subjects.

2. Measurements are limited to the researcher's ability to accurately operate cone-beam computed tomography images.

3. 3-dimensional scans may have artifacts from subject movements and machine specifications.

4. The study is limited to the subjects in the database of New Hope Orthodontics, which is the private practice of Dr. Mary E. Burns.

\section{Delimitations}

1. The skeletal ages of subjects in the sample have a cervical vertebra maturation stage (CVMS) of 4 or greater.

2. One researcher measures and evaluates all data from CBCT scans.

3. All pre-surgical scans are with the surgical splint in place and taken in centric relation. 


\section{CHAPTER 2: REVIEW OF LITERATURE}

\section{Introduction to Sleep Apnea}

Sleep apnea is often first identified by a family member who may observe an episode of sleep disordered breathing such as gasping for air. Sleep apnea does not discriminate, Young et al., estimated that " 1 in 5 adults has at least mild OSA and 1 in 15 adults has at least moderate OSA. Sleep apnea can affect anyone at any age, even children" ${ }^{\prime 13}$. According to the U.S. Department of Health, 12 to 18 million adults are affected by sleep apnea while many more go undiagnosed $^{35}$. Risk factors that predispose an individual to OSA include, but are not limited to male gender, increased neck size or small chin/jaw size, those over 40 years of age, airway anatomy and a body-mass index $(\mathrm{BMI})^{2,3,8,12}$.

\section{Diagnosis of Sleep Apnea}

According to the American Academy of Sleep, apnea is pause in breathing that lasts at least 10 seconds. These pauses in airflow can occur several times per hour. On the other hand, hypopnea is defined as a decrease in airflow that persists for at least 10 seconds $^{5,12,15}$. This is different from apneas in that there still some air that is being exchanged during ventilation. Hypopneas are only considered to be significant if there is at least a $30 \%$ reduction in air flow as well as $4 \%$ or greater desaturation in oxygen levels ${ }^{5,12}$.

The Apnea-Hypopnea Index (AHI) is employed to determine the severity of obstructive sleep apnea. In terms of severity, mild OSA is described as an AHI between 5 and 15, with 
symptoms of sleepiness. Moderate OSA would be identified if a patient has an AHI between 15 and 30. While severe OSA is diagnosed in individuals that have an AHI greater than 30.

Another system is often used to describe the severity of OSA in individuals. This classification system is known as the respiratory distress index (RDI). RDI measures respiratory event related arousals (RERA). Some studies have shown that RDI is a better indicator for OSA than $\mathrm{AHI}^{12}$.

\section{Complications Associated with OSA}

Individuals with obstructive sleep apnea often experience signs and symptoms that include, but are not limited to: excessive daytime sleepiness (EDS), morning headaches, cognitive impairment, depression, gastroesophageal reflux, sexual dysfunction, dry mouth and sore throat ${ }^{3,5,12,14,16}$. Other systemic problems associated with OSA are: hypertension, stroke, myocardial infarction and other cardiac abnormalities ${ }^{5,12,14,16}$.

\section{Types of Sleep Apnea}

Sleep disordered breathing (SDB) encompasses a host of disorders that involve pauses in breathing. The two major forms of SDB are: central sleep apnea (CSA) and obstructive sleep apnea (OSA). Central sleep apnea does not involve blockage of the airway, but rather a lack of respiratory effort due to the brain not sending the correct signals to respiratory muscles ${ }^{12}$. Obstructive sleep apnea on the other hand is due to physical blockage of the airway at one or 
more regions. OSA results in airflow disruption due to collapse of surrounding tissues in the upper airway. Of these two types of sleep disordered breathing, OSA accounts for more than $85 \%$ of sleep apneas, while CSA is less frequent ${ }^{12}$.

\section{Non-Surgical Treatment for Sleep Apnea}

Non-surgical treatment for OSA can begin with behavioral changes that encourage weight-loss, abstaining from alcohol, antihistamines, smoking, sedatives or change in sleeping position $^{5,12,15}$. When the above modifications do not produce the significant differences in OSA symptoms, then more aggressive treatment is warranted. Continuous positive airway pressure (CPAP) is currently the gold standard for non-surgical treatment of OSA. CPAP works as a pneumatic stent, opening the upper airway by continuous pressurized air flow. Although this appliance is very effective when used properly, compliance can be as low as $40 \%$ due to, "physical discomfort associated with wearing the unit, drying of the nasal and oral mucosal membranes, dislodgement during sleep, noise and the social consequences of using the unit ${ }^{1}$. 
Figure 1. CPAP Machine M $^{36}$

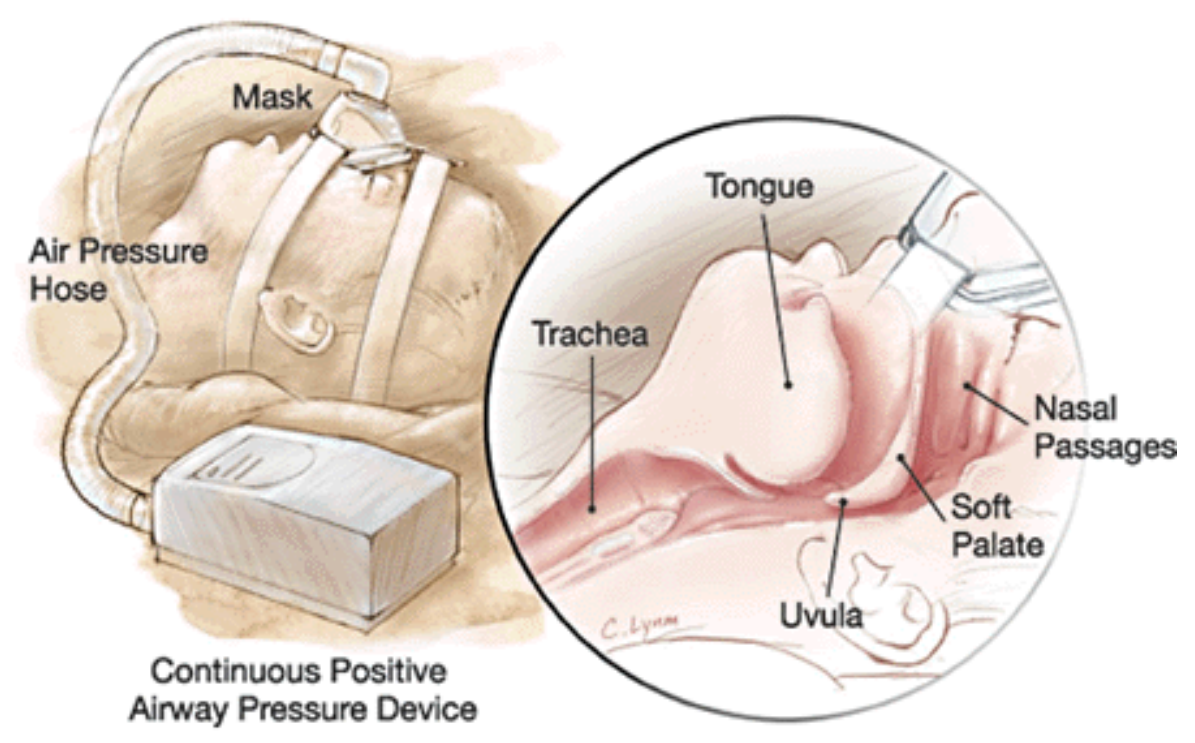

When patients cannot tolerate CPAP therapy, oral appliances (OA) can provide an alternative means of treatment. These devices are generally better tolerated than CPAP treatment because they are less cumbersome and can partially alleviate symptoms of obstructive sleep apnea $^{12,14,15}$. The two most common OA therapies involve tongue retaining devices (TRD) and mandibular advancement devices (MAD). Both of these treatment modalities have been shown to improve show improvements in patients with OSA. The TRD works by creating a suction when the tongue in placed in the bubble. This holds the tongue more anteriorly in hopes of opening the upper airway ${ }^{36}$. 
Figure 2. Tongue Retaining Device ${ }^{36}$ (TRD)

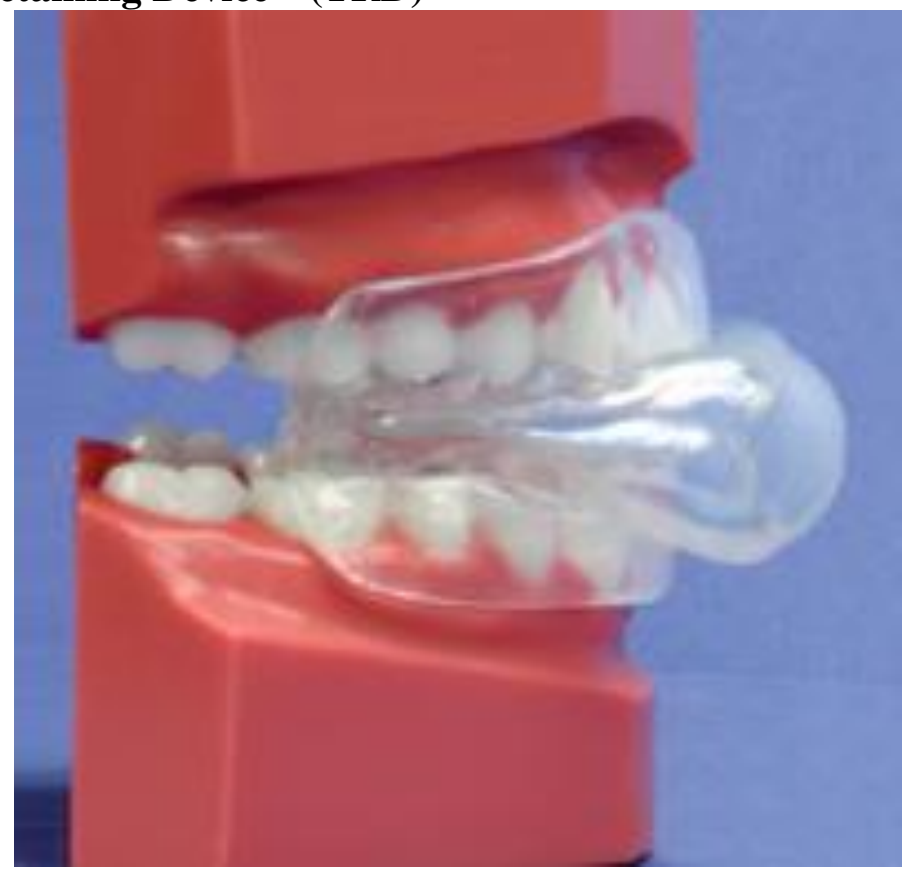

Mandibular Advancement Devices (MAD) have been shown by several studies to improve airway patency and OSA symptoms, but can have unfavorable dental side effects ${ }^{37}$. This device holds the mandible more forward thereby increasing the posterior airway space. These devices must be custom made for each patient and adjusted by a dentist in order to be effective. 
Figure 3. Mandibular Advancement Appliance ${ }^{36}$

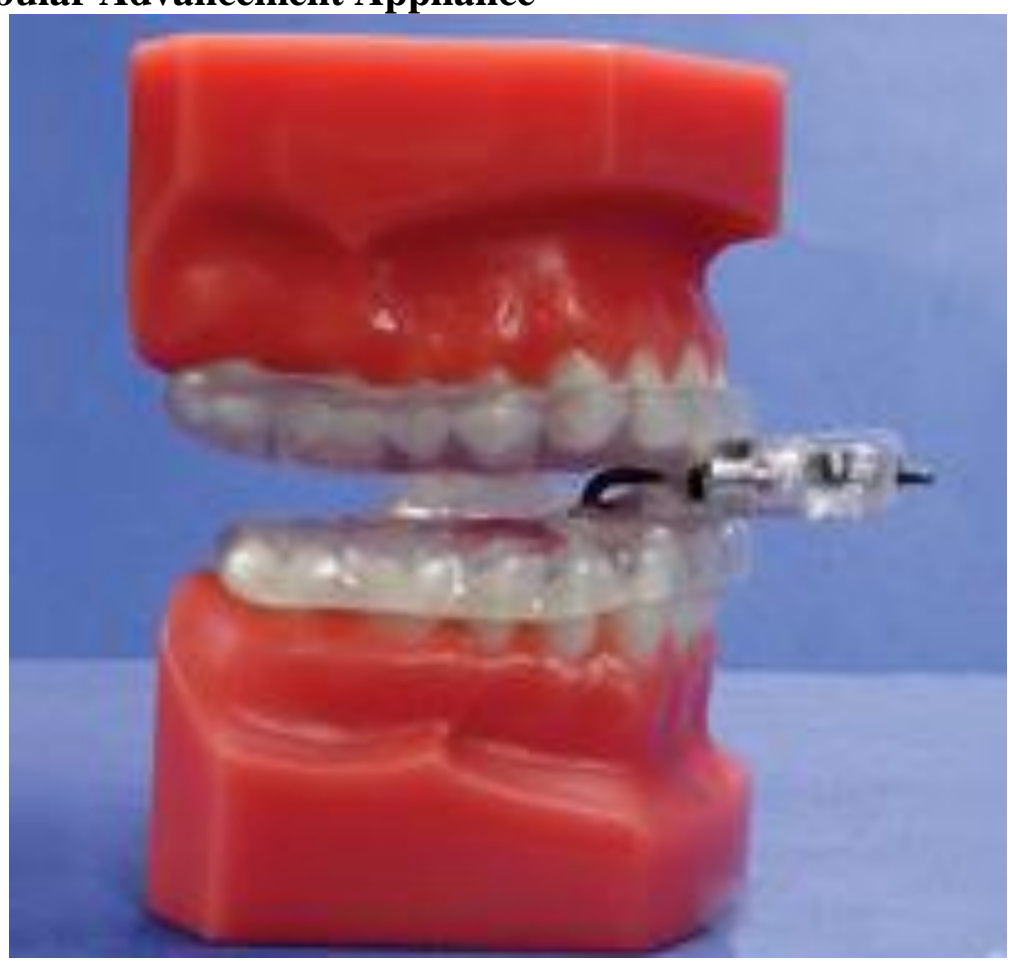

\section{Surgical Treatment for Sleep Apnea}

When non-surgical approaches are not tolerated well by patients, a surgical approach to clear the obstruction is warranted. Surgical treatment for sleep apnea is classified as either phase I treatment or phase II treatment. Phase I treatment is generally considered to less invasive and is the $1^{\text {st }}$ course of action to permanently alleviate symptoms of OSA. Phase I treatment includes: Nasal reconstruction, uvulopalatopharyngoplasty (UPPP), genioglossus/hyoid suspension and tongue reduction $^{3,5}$. Nasal obstruction is seen when an individual has a deviated septum, hypertrophic turbinates or nasal valve stenosis. In this case, nasal reconstruction can correct the obstruction and decrease nasal resistance to airflow. 
In the case of a retropalatal obstruction, UPPP is the procedure of choice. It was first introdouced by Fujita in 1979, but has since been revised". This surgery involves "removal of part of the soft palate, uvula, and tonsils, as well as part of the pharyngeal wall"15. UPPP continues to be well-accepted even though reviews have reported improvement in less than 50\% of patients and total management of OSAS in fewer than $25 \%$ of patients. The explanation for the very small success rate may lie in the fact that the UPPP addresses only one location of a multi-site problem ${ }^{3,9,11,12}$.

\section{Figure 4. UPPP Procedure ${ }^{11}$.}
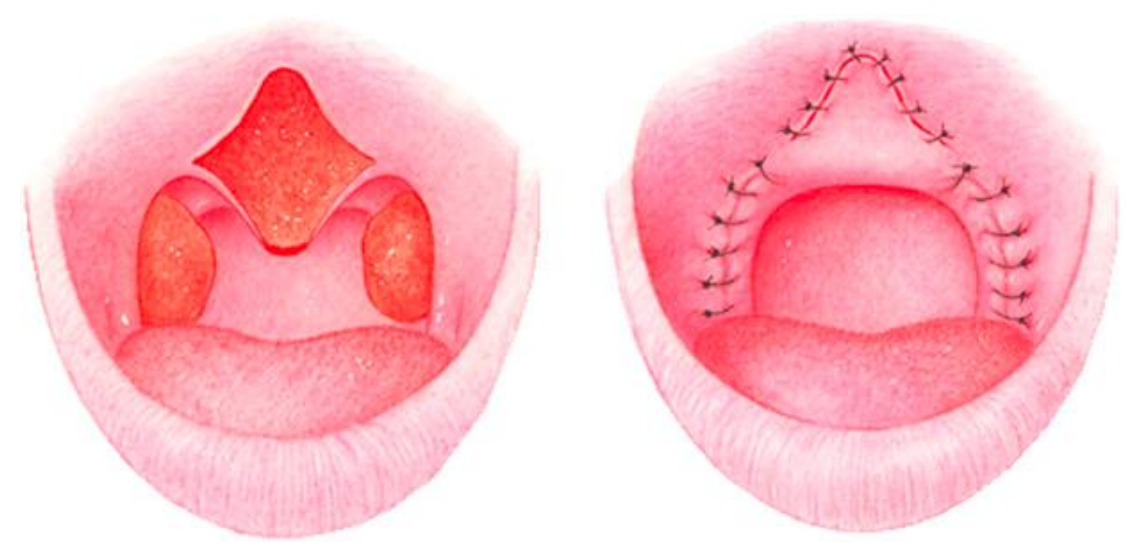

When phase I treatment fails (UPPP or nasal reconstruction), orthognathic surgery is judged to be the subsequent step in treating patients with obstructive sleep apnea. Orthognathic surgery is categorized as phase II surgery. Maxillomandibular advancement surgery is now the treatment of choice in terms of orthognathic procedures to treat OSA. According to Schendel et al., "the goal of surgical treatment of OSA syndrome is to enlarge the velo-pharyngeal airway by anterior/lateral displacement of soft tissues and musculature by maxillary, mandibular, and possibly, genioglossus advancement" ${ }^{\prime 10}$. 
Figure 5. Maxillomanidbular Advancement Surgery ${ }^{11}$

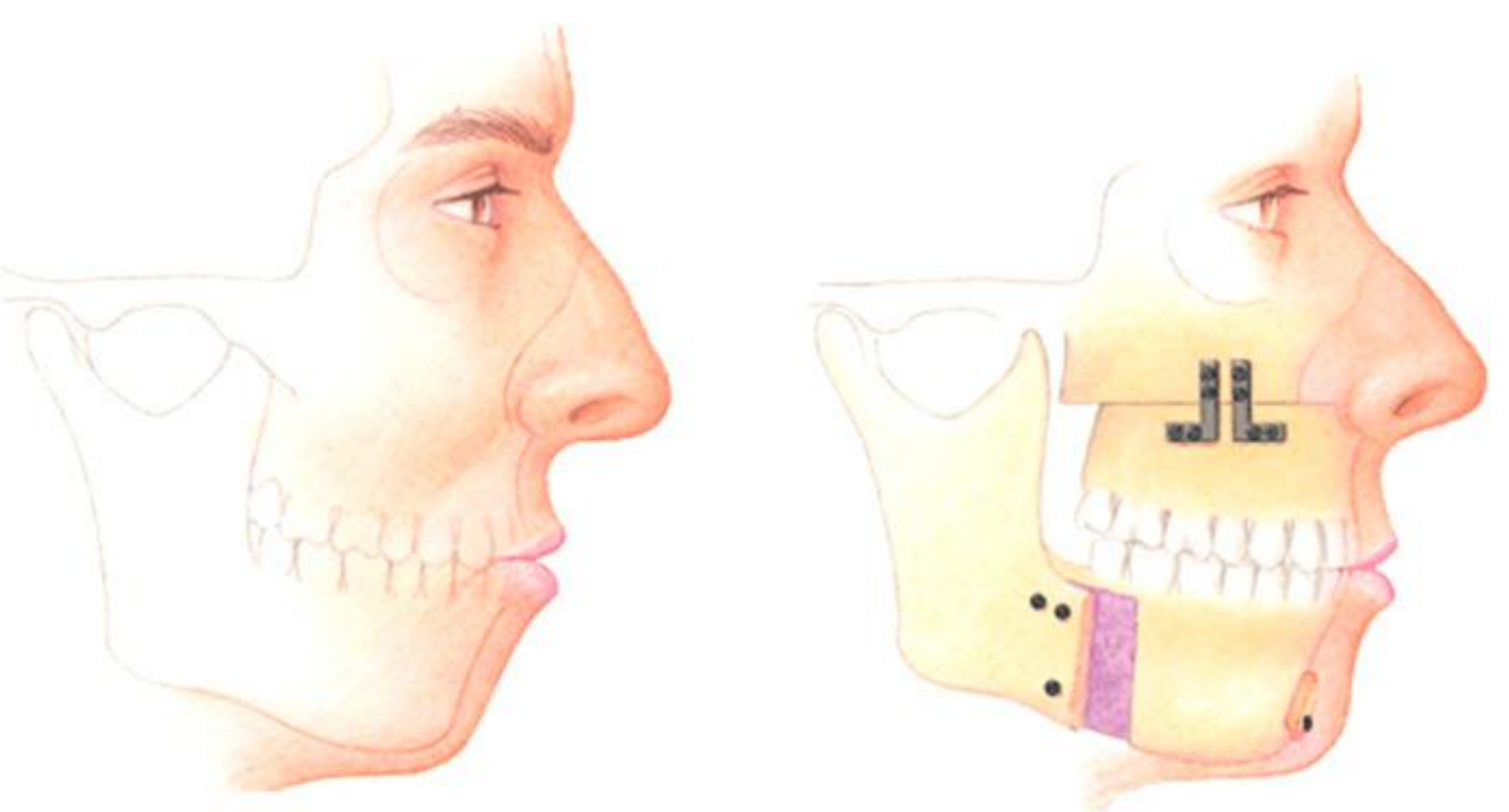

\section{Physics of the Airway}

The airway is essentially composed soft tissue that is has the potential to collapse when muscles relax during sleep. The likelihood of collapse of the airway increases when persons have the following predispositions: 1) craniofacial abnormalities or 2) large fat deposits which can add extra pressure on the surrounding airway soft tissue ${ }^{12}$. 
Figure 6. Airway changes with weight gain or craniofacial micrognathia ${ }^{12}$

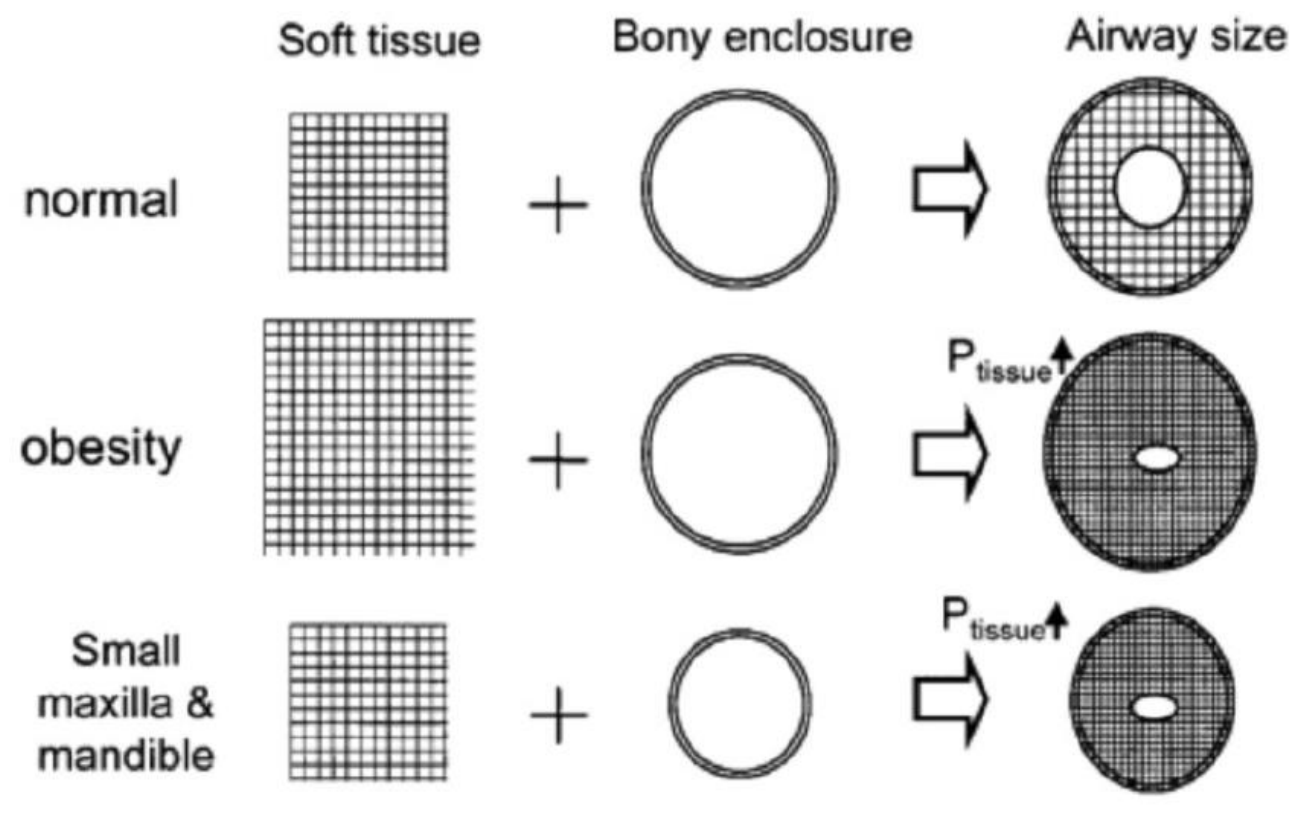

\section{Traditional Cephalometric Airway Analysis}

The most widely used orthodontic airway analysis was derived by McNamara in 1984.

This analysis consists of measuring the airway using a 2D cephalometric image. The McNamara analysis utilizes only two measurements taken from a lateral cephalogram to examine the possible airway dysfunction ${ }^{38}$. However, these values only give information on 2 sites where as airway obstruction can occur at multiple sites and therefore this analysis is not useful in diagnosing OSA in adults. 
Figure 7. McNamara Airway Analysis ${ }^{38}$

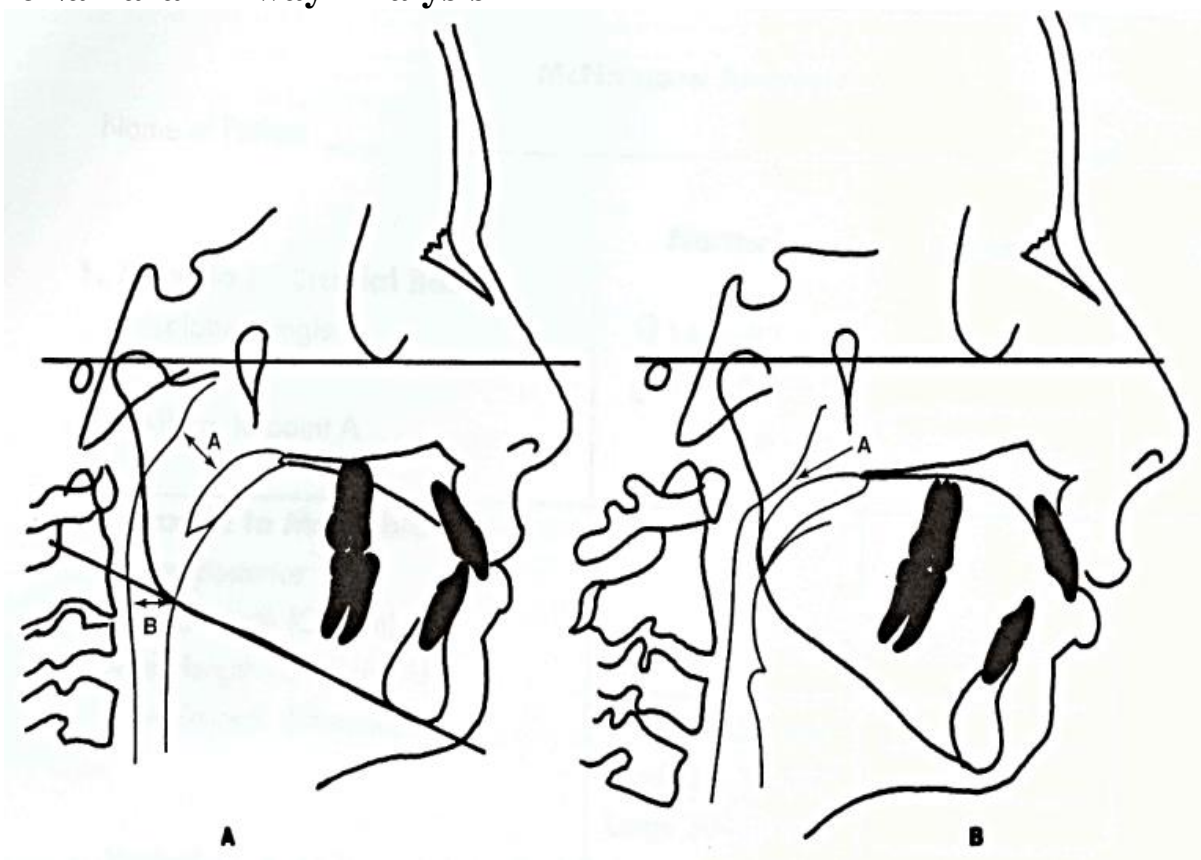

\section{Current Questions Still Unanswered}

Given that CBCT imaging is a fairly recent technology, there have not been many airway evaluation studies conducted utilizing this technology. The effect on the airway from more than a 2-dimensional perspective is needed. Moreover, a comparison of 2-dimensional versus 3dimensional analysis of similar regions of the airway is also essential to understand the validity of past studies. 


\section{Orthognathic Surgery}

Orthognathic surgery is often necessary for individuals that show evidence of jaw discrepancies that cannot be compensated for with orthodontic treatment alone. In this case, surgical procedures can help produce a more harmonious facial balance and optimal occlusion ${ }^{18}$. Often when there is a severe antero-posterior discrepancy, the airway can be either improved or get worse.

\section{Airway Changes with Class III Correction}

Many patients that present with a class III malocclusion can only be treated with orthognathic surgery. Studies have shown that there is a decrease in the airway following mandibular setback surgery alone $\mathrm{e}^{39-41}$. This may due to "inferior repositioning of the hyoid bone and posterior displacement of the tongue and the soft palate. These movements cause anteroposterior and lateral narrowing of the $\mathrm{PAS}^{26 \%}$.

Therefore, other researchers suggest bimaxillary surgery which consists of a maxillary advancement and mandibular setback, when a severe antero-posterior discrepancy exists ${ }^{42-45}$.

\section{Airway Changes with Mandibular Advancement Alone}

A cephalometric study by Achilleos et al., suggests that there is long-term increase in airway dimensions after mandibular advancement alone ${ }^{46}$. However, another long-term followup study by Eggensperger et al., indicates that after an initial increase in PAS, there was 
significant relapse after mandibular advancement alone ${ }^{47}$. Consequently, the current recommendation for phase II OSA treatment is maxillomandibular advancement surgery as opposed to mandibular surgery alone because OSA is known to be a syndrome that occurs at multiple sites along the airway and not a single area.

\section{Airway Changes with Maxillomandibular Advancement}

Maxillomandibular advancement surgery was not always the preferred method to treat OSA. In fact, until 1979, tracheosteomy was often the treatment method for OSA patients that could not tolerate other sleep apnea therapies ${ }^{48}$. MMA consists of advancement of the maxilla by a Lefort I osteotomy as well as advancement of the manidbular by a bilateral sagittal split osteotomy. Advancement of upper and lower jaws allows for concurrent advancement of the suprahyoid and velopharyngeal muscle attachments, thereby opening the airway.

According to the literature, MMA has been shown to consistently increase posterior airway space. This increase in airway occurs due to elevation of structures attached to the maxilla, mandible, and hyoid as well causing increased tension on pharyngeal muscles ${ }^{26}$. However, most of this research has been conducted using lateral cephalometric measurements and these measurements do not take into account the transverse changes in the airway after orthognathic surgery. 


\section{Stability of Maxillomandibular Advancement}

Maxillomandibular advancement surgery for patients with obstructive sleep apnea usually consists of advancements of $1 \mathrm{~cm}$ in distance. There have been critics that believe that such large advancements may not be stable. However, long-term follow research has shown that

the results of MMA surgery are stable $27,49-53$. Stability may be due to the advent of rigid internal fixation which helps to secure the skeletal segments during large surgical movements.

\section{Dental Radiographs}

Traditional radiographs have limited diagnosis potential since they are only a 2dimensional perspective. In fact, there many are advocating the use of $\mathrm{CBCT}$ imaging in place of a panoramic, lateral cephalometric and periapical radiographs. The radiation dose of a CBCT scan can also be adjusted by using a smaller field of view that would still provide the necessary data, but provide a lower dose of radiation.

\section{Cone Beam Computerized Tomography (CBCT)}

Cone beam computed tomography (CBCT) imaging, is a relatively novel approach to imaging. CBCT was first introduced in the 1990s, and is currently in over 3,000 dental offices. The advent of CBCT allowed the use of a 3-dimensional imaging in dentistry with largely reduced radiation exposure, shorter scan times, and less costs when compared to conventional computed tomography used in the medical field ${ }^{54}$. Cone beam scanners obtain their images by 
directing $\mathrm{x}$-rays in a divergent cone, thereby acquiring hundreds of images while the scanner revolves around the patient's head. These images are then reconstructed by software programs like Dolphin 3D, in order to obtain a diagnostic quality volumetric image that can then be analyzed.

Figure 8. CBCT scanning technology ${ }^{55}$.

\section{Cone Beam X-ray \& Flat Panel Detector}

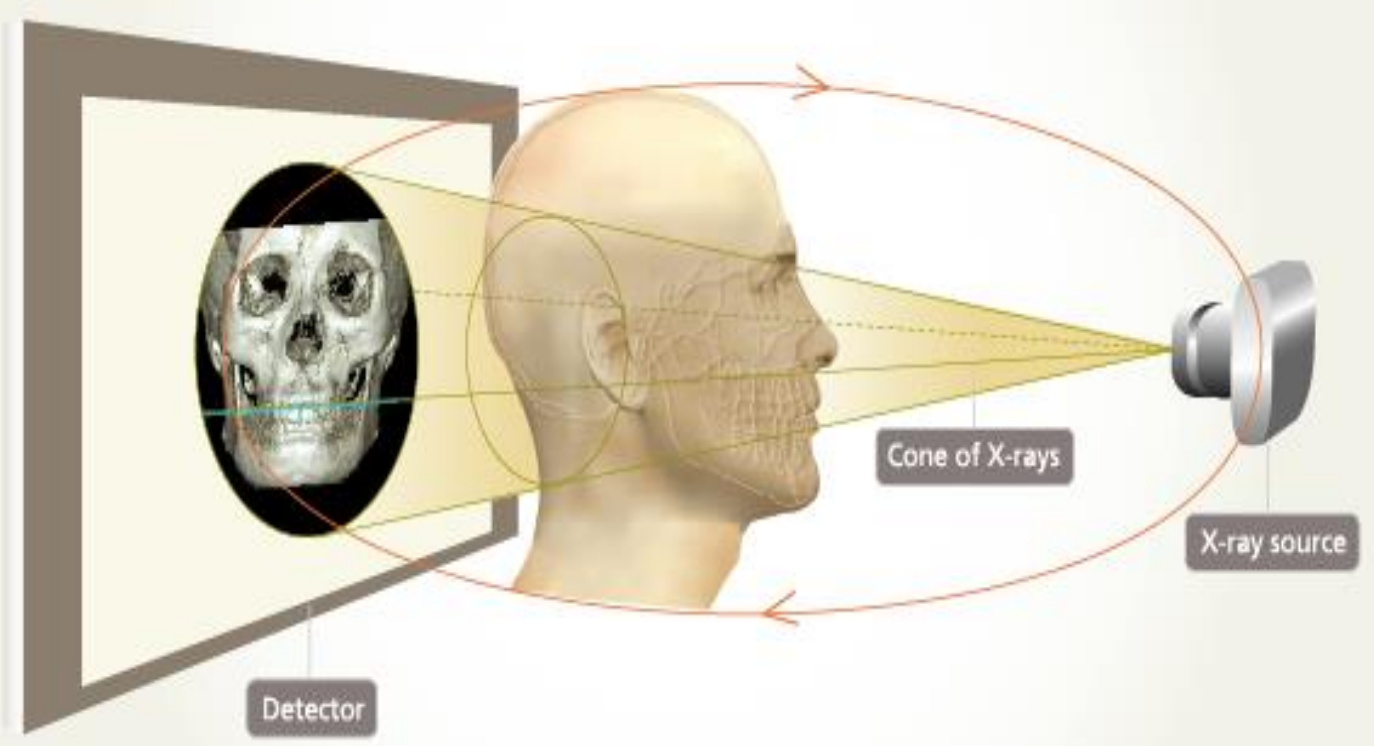

\section{CBCT Image Accuracy}

Cone beam computed tomography is a superior imaging technology in of itself due to the fact that it allows for a 3-dimensional representation of anatomic structures. However, there 
have been questions raised as to how accurate $\mathrm{CBCT}$ images are and if they are comparable to 2dimensional radiographic techniques.

Several studies have been completed comparing the accuracy of anatomic data obtained from lateral cephalograms and $\mathrm{CBCT}$ images. Both studies concluded that $\mathrm{CBCT}$ is useful tool for analysis posterior airway space. The authors also found that there was variability in volumetric measurements even though the airway dimensions appeared to be similar in the lateral cephalograms. This suggests that one cannot get true story of airway dimensions from an 2-dimensional image ${ }^{17,56}$.

In 2007, Moshiri et al. compared the accuracy of linear measurements taken from CBCT images to those measurements taken from traditional cephalometric headfilms. The investigation found that lateral cephalometric images rendered from CBCT data were more accurate than traditional lateral cephalometric headfilms ${ }^{57}$.

Periago et al. studied the accuracy and reliability of linear measurements from cone beam images taken from measurements on human skulls and then reconstructed with an orthodontic volumetric rendering program ${ }^{58}$. The study found that the linear measurements taken on reconstructed 3D images can be different from anatomic dimensions. However, most measurements could be considered to be sufficiently clinically accurate for craniofacial analyses.

\section{Radiation Safety}

When it comes to radiation safety and what is a safe dose for any sort of imaging, one should consider the risks and rewards associated with the exposure. Cone beam computed 
tomography can have 4 times less radiation exposure than conventional CT imaging, but it is dependent on the adjusted settings for the CBCT machine ${ }^{59}$. For example, les radiation exposure can be achieved if a lower $\mathrm{mA}$ and collimation setting is selected for a particular machine ${ }^{60}$. The effective patient dose from a CBCT has been reported as low as $45 \mathrm{uSv}$, but when the settings are modified to give the patient a lower dose, there is often a compromise in the quality of the image produced. As a reference, the average exposure for a full-mouth series of radiographs has been reported to be approximately $150 \mathrm{uSv}$, which a panoramic radiograph has been detailed to be $54 \mathrm{uSv}^{61,62}$. Therefore, the use of CBCT imaging for 3-dimensional volumetric imaging can be justified for patients with suspected airway compromise as long as the effective dose of the scan is kept as low as reasonably possible.

\section{CBCT Benefits, Limitations, and Applications within Orthodontics}

There are many benefits to cone beam tomography when compared to traditional cephalometric radiography. Cephalometric radiography disadvantages include the following: Superimposition of left and right structures, magnification errors, and difficulty in identifying key points (i.e. A point). According to an article by Lenza et al., linear measurements on cephalograms are far less clear than 3-dimensional analysis of similar structures ${ }^{63}$.

CBCT imaging is becoming more popular in the dental community because it can be advantageous in implant placement, identifying impacted teeth, and skeletal asymmetries just to name a few. Cone beam images are not only 3-dimensional, but also provide an image with no magnification consequently the image is a 1:1 scale. Another benefit of CBCT data is the fact that hard and soft tissue analysis is available at the same time and the operator has the ability to 
rotate and view airway from all perspectives ${ }^{19,57,64}$. An additional and major advantage of cone beam computed tomography when compared to lateral cephalograms is that it allows for detailed assessment and accurate quantitative measurements of cross-sectional area and volume to help identify areas of obstruction.

However, although CBCT is a tremendous tool in evaluating airway parameters, it does have limitations when evaluating the airway. One of the limitations is that it is a static evaluation of a dynamic structure. Another limitation is the fact that airway dimensions have been shown to change depending on the stage of the breathing. Most dental CBCT machines acquire their scans in an upright position. However, the airway volume has been demonstrated to change when a patient is in a supine position ${ }^{65}$. Therefore this is another limitation that should be kept in mind when evaluating airway volume and cross-sectional data.

\section{The Current Question}

There is clear evidence that MMA surgery improves airway patency in patients with sleep apnea ${ }^{2,9,16,24,26-30,32,51,53,65,66}$. However, much of this research was conducted using a 2dimensional cephalograms. This study determines which specific area of the airway is most significantly impacted by maxillomandibular advancement with counterclockwise rotation of the occlusal plane. This study compares 2-dimensional measurements to 3-dimensional measurements of the airway at certain points to determine if there is a correlation in the results. 


\section{CHAPTER 3: EXPERIMENTAL DESIGN AND METHODS}

\section{Imaging Protocol}

This study is in collaboration with Dr. Mary E. Burns, clinical orthodontist, in New Hope, Pennsylvania. The DICOM files used were de-identified before they were utilized for this study. The cone-beam computer tomography scanner used to take the volumetric images was a Kodak CS 9300.

A total of 28 subjects pre- and post-surgical CBCT scans were evaluated. All of the individuals underwent maxillomandibular advancement with a counterclockwise rotation of the occlusal plane. Although not all patients were diagnosed with obstructive sleep apnea, but did illustrate airway constriction at one or more levels along the posterior airway space (PAS). The average age for the subjects was 35 years +/- 17 years, with a range of 14-63 years.

\section{IRB Approval}

Cone-beam images used in this study were reviewed and exempted by the Institutional Review board at West Virginia University (Appendix A). 


\section{Methodology}

All DICOM files were analyzed using Dolphin 3D Imaging 11.5, licensed to West Virginia University Department of Orthodontics. The 3D volumes were segmented to obtain the clearest representation of the airway and related structures. Orientation of the images were accomplished by using the following planes: 1) the horizontal plane, also known as axial plane, was determined by constructing a line through the lowest border of the infra-orbital rims and, 2) the vertical plane, also known as the mid-sagittal plane, was determined by constructing a line through ANS and the dental midline.

Figure 9. Image Orientation.

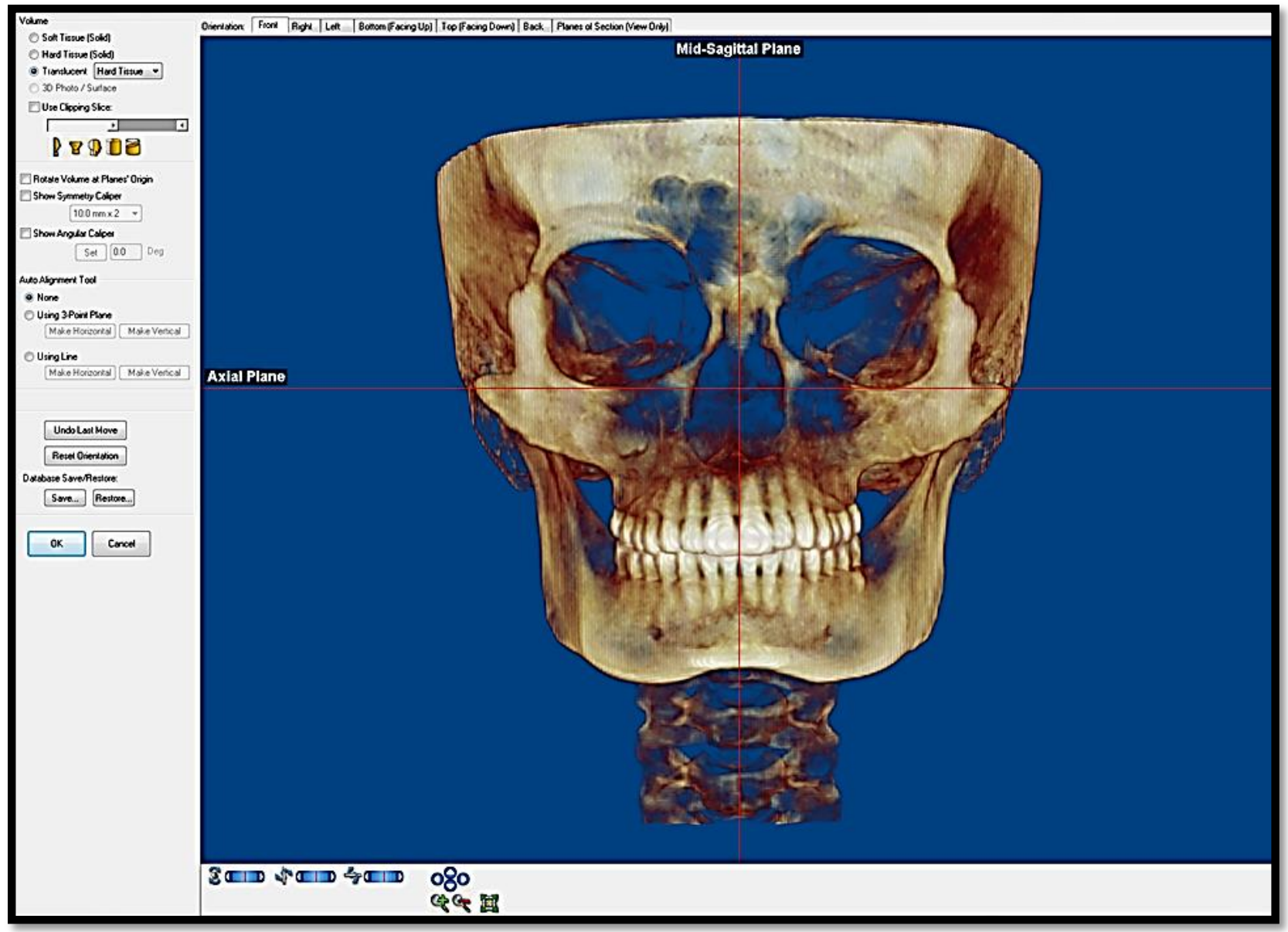


Following orientation of the pre- and post- surgical images, the CBCT volume was used to create right lateral cephalograms which were then used for linear cephalometric measurements. The 3D volume was also utilized to find cross-sectional measurements from axial slices taken from the cone-beam images at specific points. Finally, CBCT images were used to find volume measurements at explicit regions along the posterior airway space.

The sites for the posterior airway space assessment were chosen as the landmarks were easily and reproducibly identified on 2-dimensional and 3-dimensional images. Utilization of these references and landmarks allowed for standardized data collection, thus minimizing the chances of invalid calculations. The method used for evaluation of the airway was adapted from an article by Park et $\mathrm{al}^{44}$.

\section{Image Analysis for Linear Cephalometric Measurements}

The following cephalometric reference points were used to analyze the cephalograms:

- Po (Porion): The most superior point of the external auditory meatus

- Or (Orbitale): The most inferior point of the orbital margin

- PNS: The most posterior point of the hard palate

- CV1: The most anterior inferior point of the anterior arch of the atlas

- CV2: The most anterior inferior point of the body of the $2^{\text {nd }}$ cervical vertebra

- CV3: The most anterior inferior point of the body of the $3^{\text {rd }}$ cervical vertebra

The following cephalometric reference planes were used to analyze the cephalograms:

- FH plane (Frankfort Horizontal): The plane constructed through Po and Or 
- PNS Plane: The plane parallel to FH passing through PNS

- CV1 Plane: The plane parallel to FH passing through CV1

- CV2 Plane: The plane parallel to FH passing through CV2

- CV3 Plane: The plane parallel to FH passing through CV3

- Anterior Airway Plane - a vertical plane through PNS, the soft palate, the base of the tongue, and the anterior wall of the pharynx

- Posterior Airway Plane - a vertical plane through the posterior wall of the pharynx

After the planes were constructed, the following measurements were then taken from the cephalograms:

- Airway at PNS - Distance from anterior pharyngeal wall to posterior pharyngeal wall at the level of PNS

- Airway at CV1 - Distance from anterior pharyngeal wall to posterior pharyngeal wall at the level of CV1

- Airway at CV2 - Distance from anterior pharyngeal wall to posterior pharyngeal wall at the level of $\mathrm{CV} 2$

- Airway at CV3 - Distance from anterior pharyngeal wall to posterior pharyngeal wall at the level of CV3 
Figure 10. Linear Analysis Method.
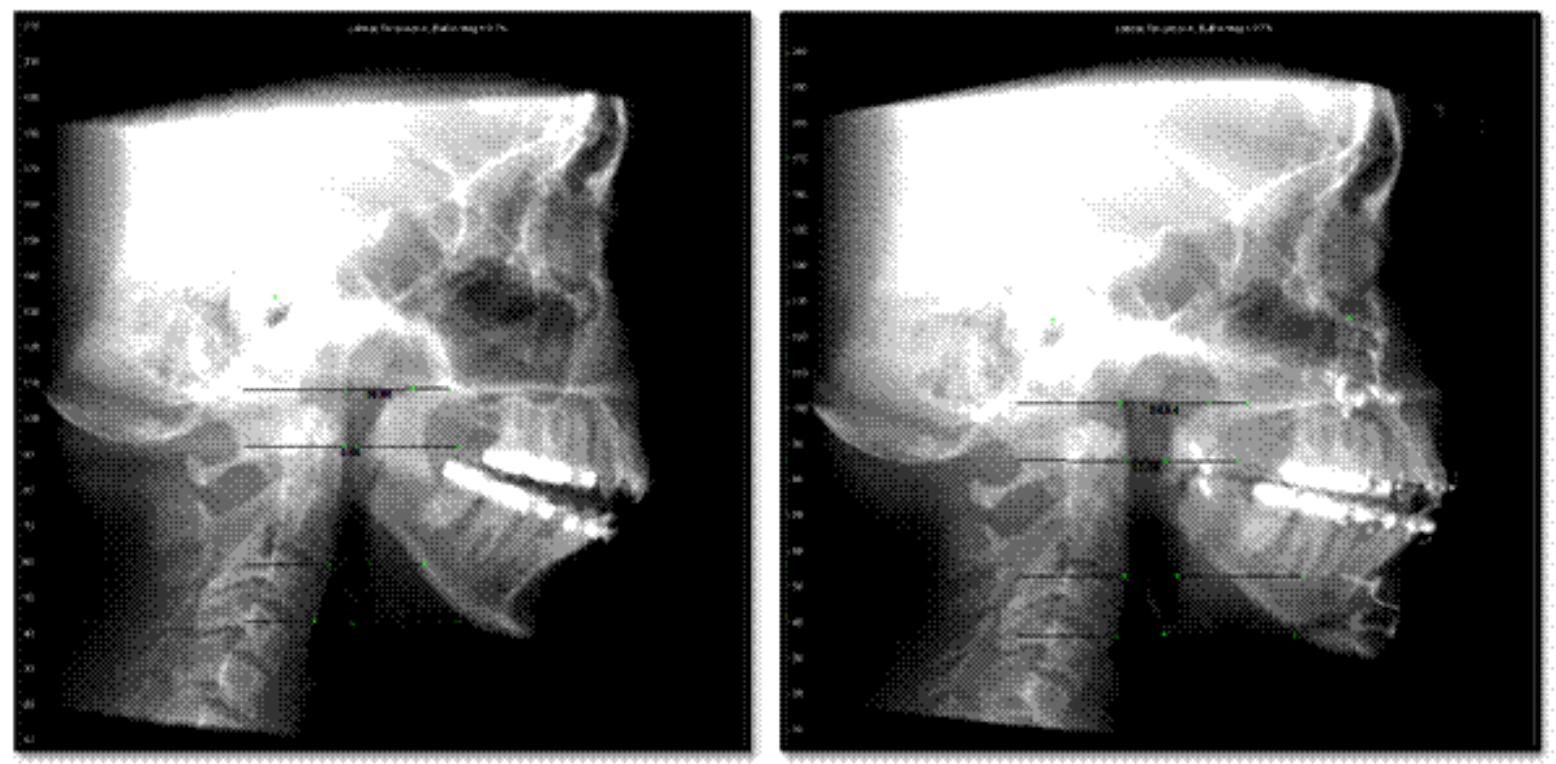

\section{Image Analysis for Planar (cross-sectional) Measurement}

The following reference points were used to analyze the 3D volume:

- Po (Porion): The most superior point of the external auditory meatus

- Or (Orbitale): The most inferior point of the orbital margin

- PNS: The most posterior point of the hard palate

- CV1: The most anterior inferior point of the anterior arch of the atlas

- CV2: The most anterior inferior point of the body of the $2^{\text {nd }}$ cervical vertebra

- CV3: The most anterior inferior point of the body of the $3^{\text {rd }}$ cervical vertebra

The following reference planes were used to analyze the 3D volume:

- FH plane (Frankfort Horizontal): The plane constructed through Po and Or 
- PNS Plane: The plane parallel to FH passing through PNS

- CV1 Plane: The plane parallel to FH passing through CV1

- CV2 Plane: The plane parallel to FH passing through CV2

- CV3 Plane: The plane parallel to FH passing through CV3

- Anterior Airway Plane - a vertical plane through PNS, the soft palate, the base of the tongue, and the anterior wall of the pharynx

- Posterior Airway Plane - a vertical plane through the posterior wall of the pharynx

Cross-sectional measurements of the airway were then calculated by using axial slices through PNS, CV1, CV2 and CV3.

Figure 11. Cross-sectional area at the level of PNS

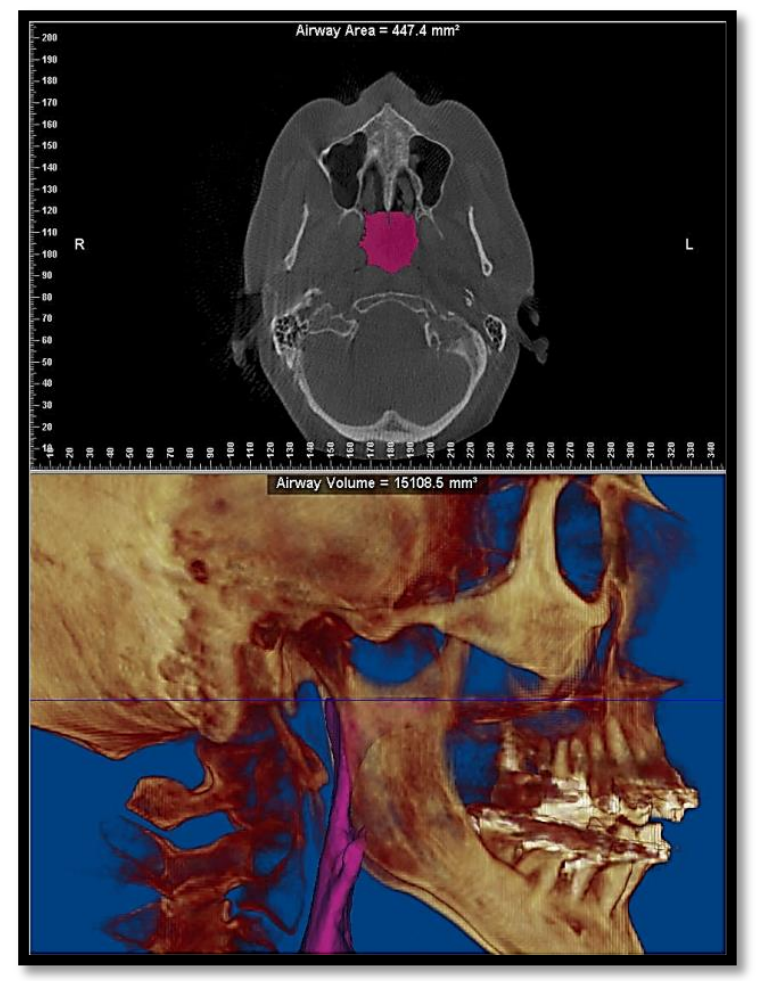


After cross-sectional measurements were taken, the minimal cross-sectional area was also found for each subject. The minimal axial area was calculated by using a specific analysis tool Dolphin 3D version 11.5.

Figure 12. Minimal Axial Area Measurement.

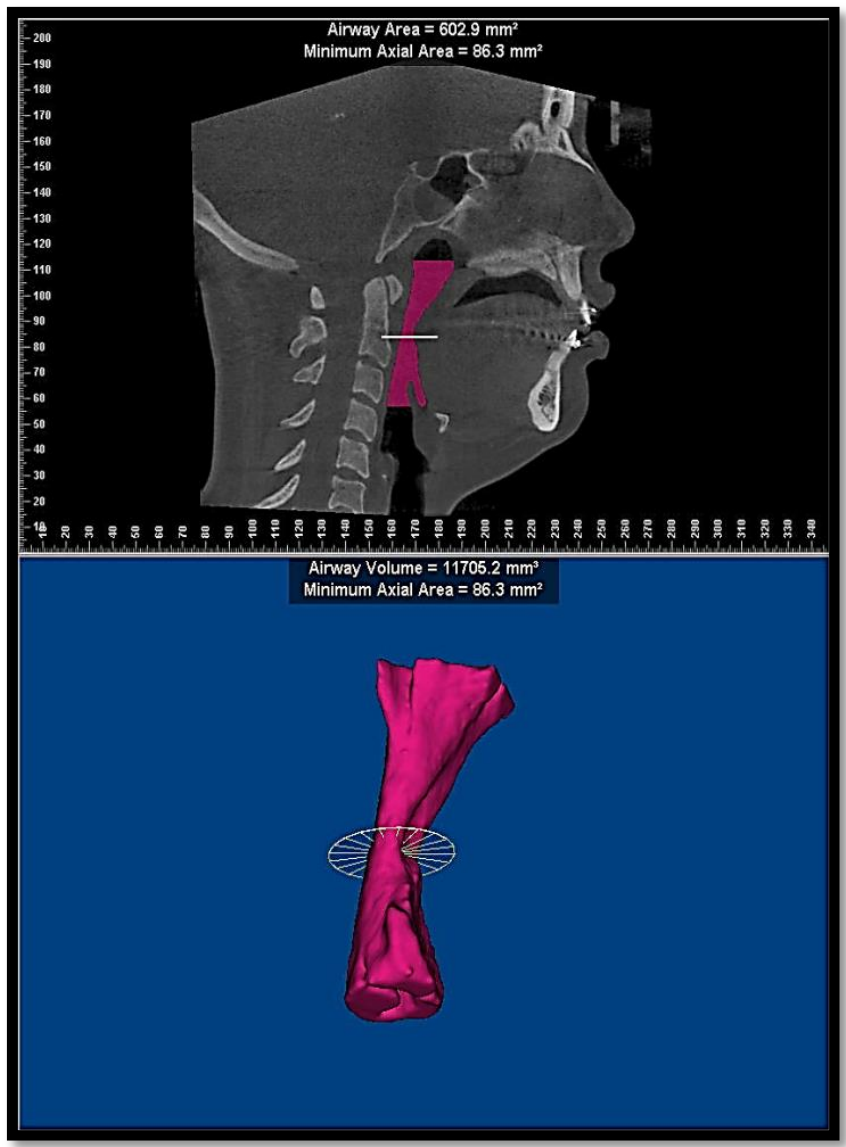




\section{Image Analysis for Volume Measurements}

Boundaries to measure posterior airway volume were as follows:

- Anterior - a vertical plane through PNS, the soft palate, the base of the tongue, and the anterior wall of the pharynx

- Posterior - the posterior wall of the pharynx

- Lateral - the lateral walls of the pharynx

- Upper - a horizontal plane passing through PNS

- Lower - a horizontal plane passing through CV3

Volumetric Measurements were calculated by delineating the following planes and then calculating the volume within these regions:

- Total Volume was found by evaluating the region between the planes tangent to PNS and CV3.

- Retropalatal (RPv) volume was found by measuring the volume between the planes tangent to PNS and CV1 and perpendicular to the sagittal plane.

- Oropharyngeal $(\mathrm{OPv})$ volume was found by measuring the volume between the planes tangent to CV1 and CV2 and perpendicular to the sagittal plane.

- Hypopharyngeal ( $\mathrm{HPv})$ volume was found by measuring the volume between the plane tangent to CV2 and CV3 and perpendicular to the sagittal plane. 
Figure 13. Total Volume Measurement.
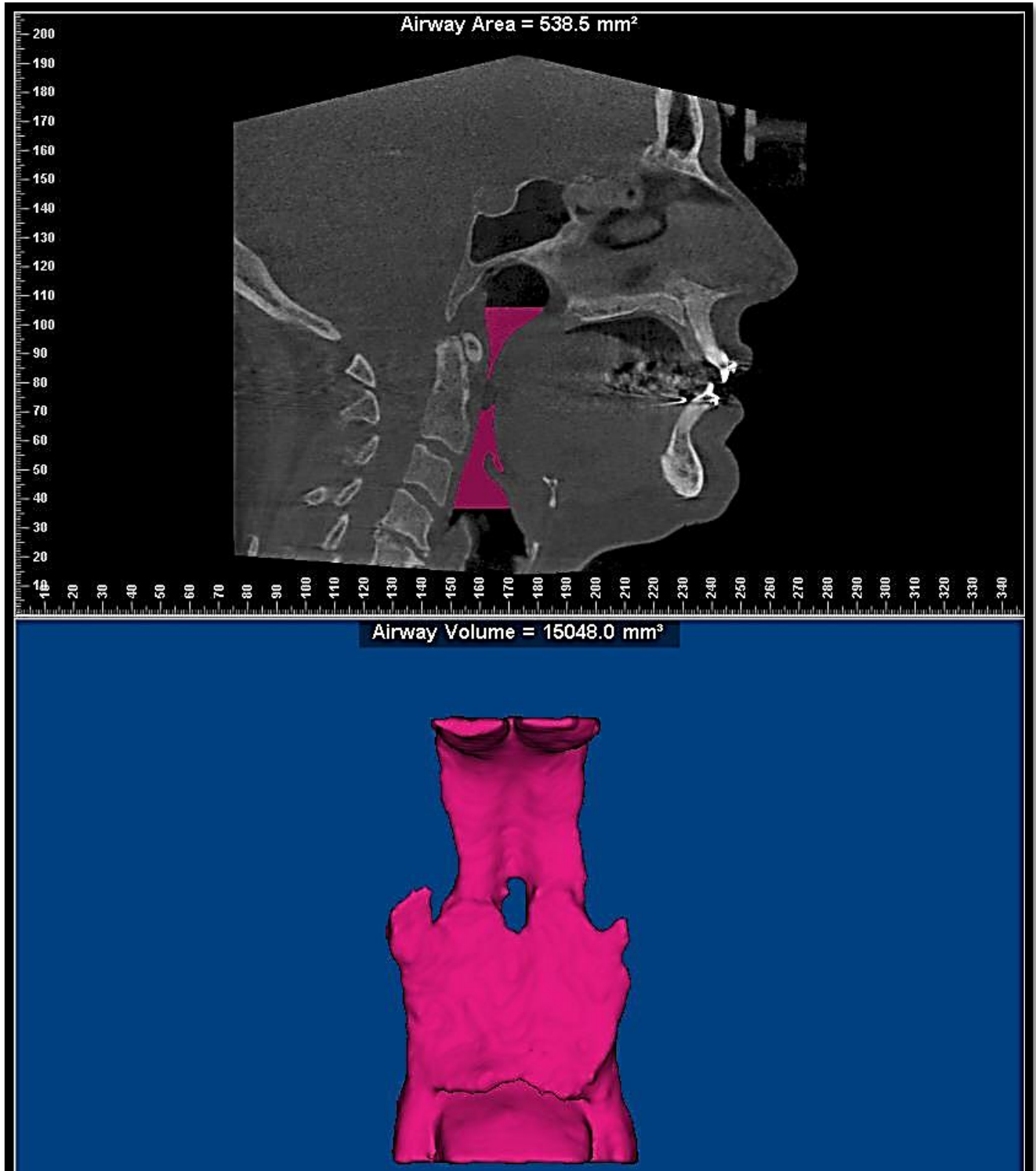
Figure 14. Retropalatal Volume Measurement.

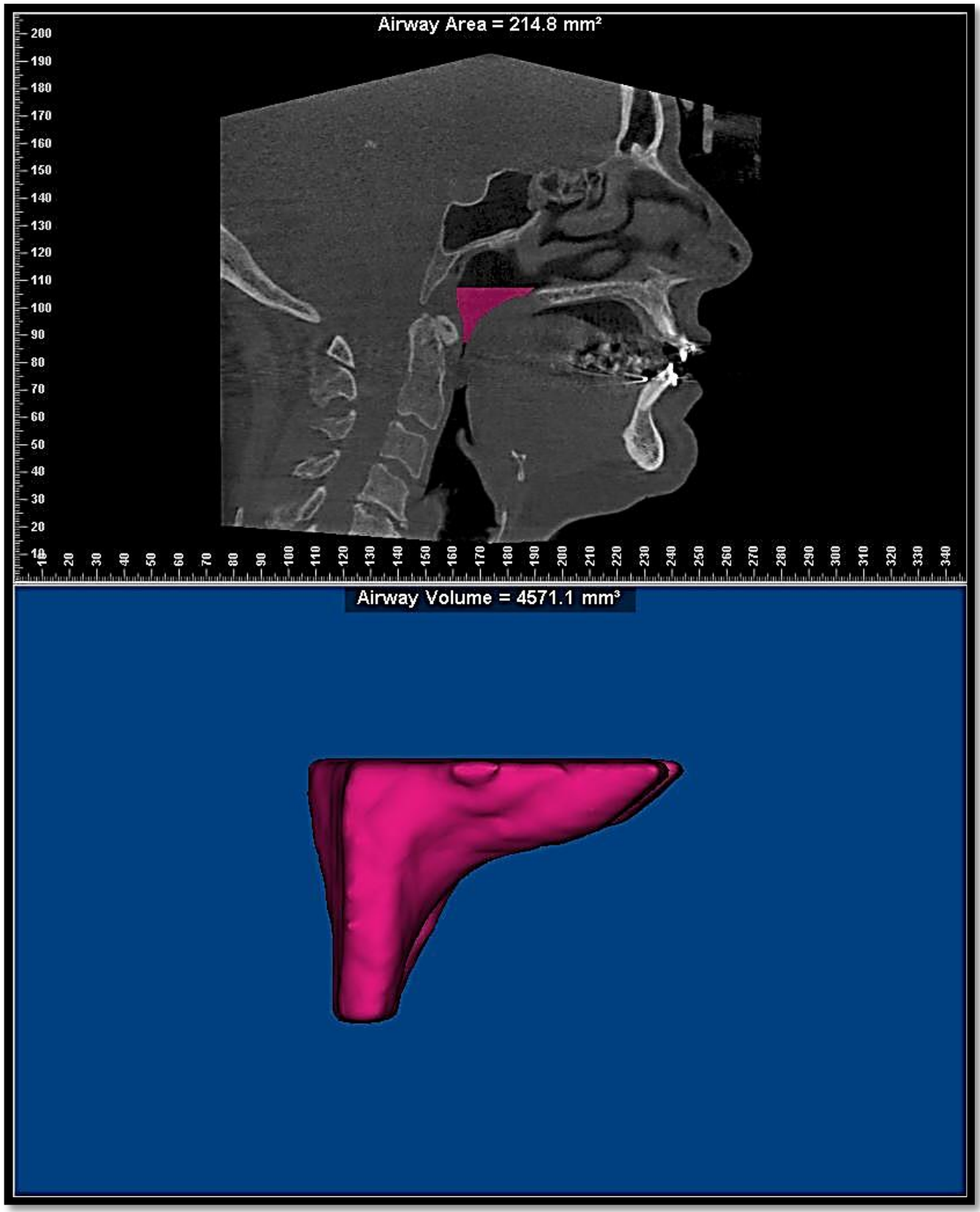


Figure 15. Oropharyngeal Volume Measurement.

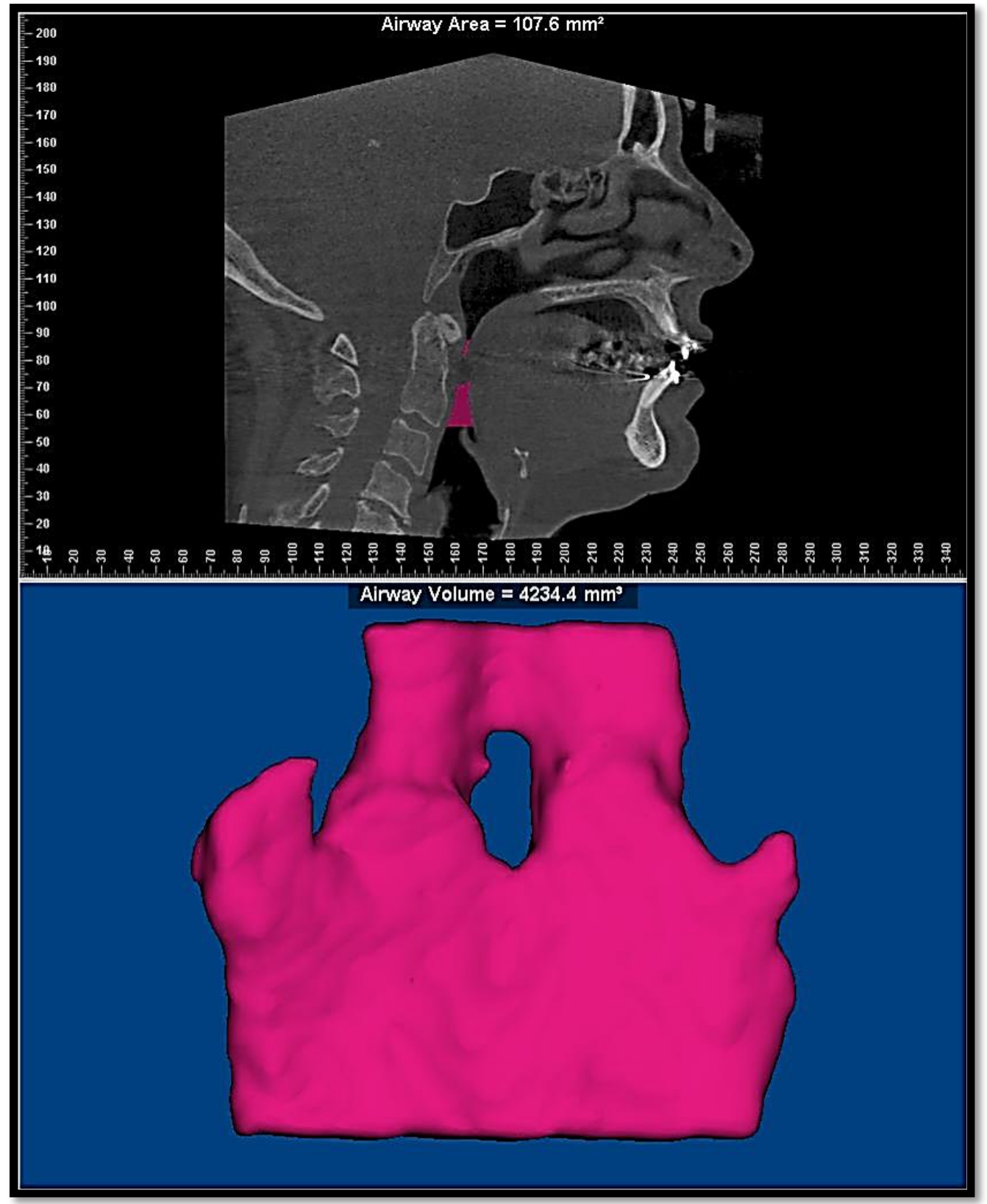


Figure 16. Hypopharyngeal Volume Measurement.

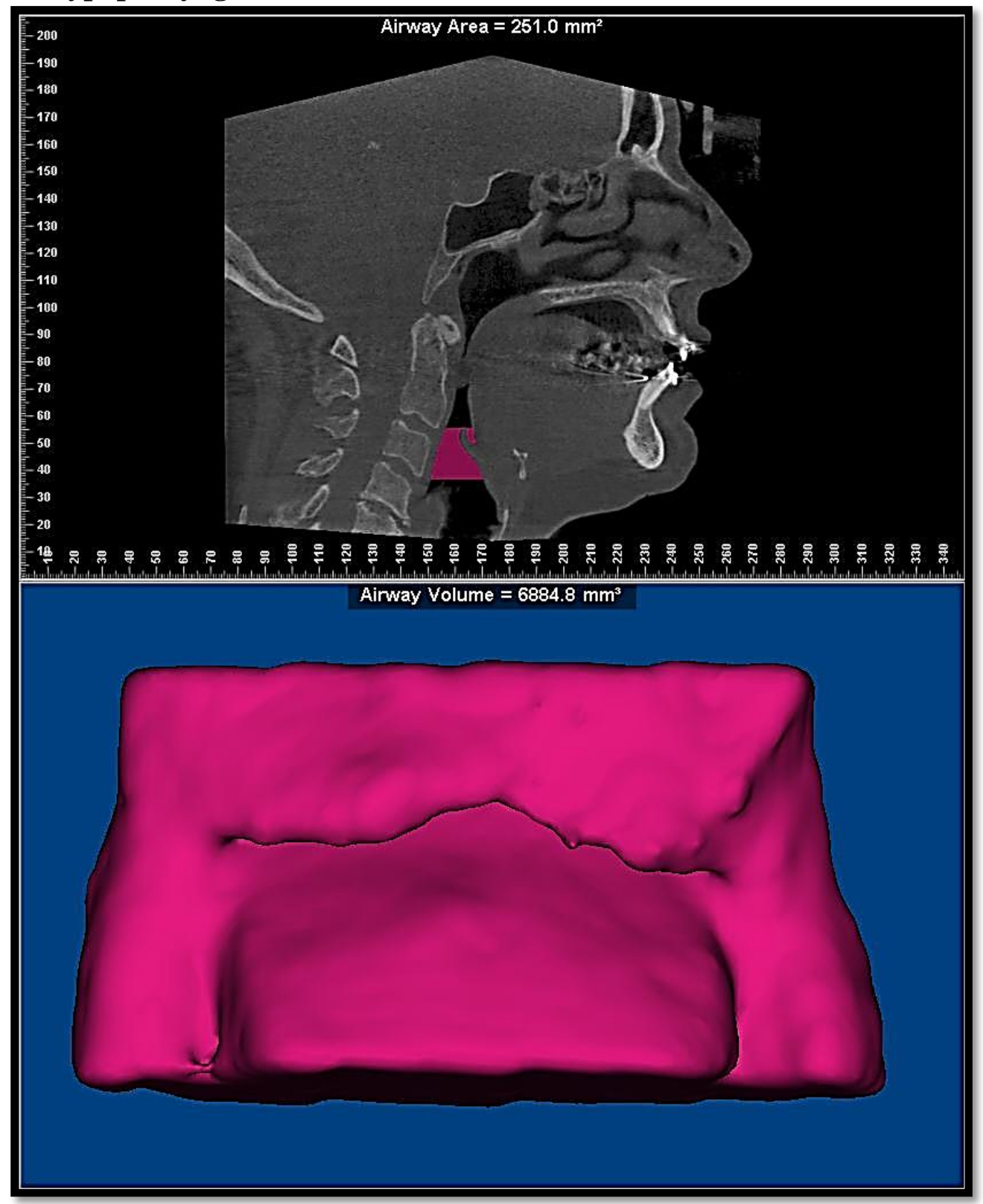

\section{Method Error}

The reliability of this three-dimensional airway analysis is tested by investigating the error in locating and measuring the changes of all landmarks. Ten subjects are analyzed a second time two weeks after the initial tracing. For all variables, differences between the measurements recorded at the first analysis and measurements recorded at the second analysis 
are compared for each of the 10 individuals. A matched-pairs reliability test was used to statistically analyze each measurement to establish a coefficient of reliability to determine the degree of reliability of the analysis.

\section{Statistical Analysis}

Means were determined for pre-surgical and post-surgical groups. Microsoft Excel 2010 SPSS data analysis tool is used to determine significance of change in airway volume, crosssectional area and linear measurements after orthognathic surgery. Further analysis will be done with data at a later time.

\section{CHAPTER 4: RESULTS}

\section{Method Error Result}

The reliability coefficient was found to determine the repeatability of the measures made for the variables in this study. When we have two measurements, the coefficient of reliability is the correlation between the first and second measurements. There is high reliability if the correlation is close to one. For all variables the correlation is 0.99 or 0.98 (Table 1). This means the first and second measurements are in agreement. Therefore, the data collected in this study is consistent and reliable. 
Table 1. Reliability Coefficient

\begin{tabular}{|l|c|l|c|}
\hline \multicolumn{2}{|l|}{ Reliability Coefficient } & \multicolumn{1}{l|}{} \\
\hline Pre-op Airway at PNS & 0.99 & Post-op Airway at PNS & 0.98 \\
\hline Pre-op Airway at CV1 & 0.99 & Post-op Airway at CV1 & 0.99 \\
\hline Pre-op Airway at CV2 & 0.98 & Post-op Airway at CV2 & 0.98 \\
\hline Pre-op Airway at CV3 & 0.99 & Post-op Airway at CV3 & 0.99 \\
\hline Pre-op PNS CS Area & 0.99 & $\begin{array}{l}\text { Post-op PNS } \\
\text { CS Area }\end{array}$ & 0.99 \\
\hline Pre-op CV1 CS Area & 0.99 & $\begin{array}{l}\text { Post-op CV1 } \\
\text { CS Area }\end{array}$ & 0.99 \\
\hline Pre-op CV2 CS Area & 0.99 & $\begin{array}{l}\text { Post-op CV2 } \\
\text { CS Area }\end{array}$ & 0.99 \\
\hline Pre-op CV3 CS Area & 0.99 & $\begin{array}{l}\text { Post-op CV3 } \\
\text { CS Area }\end{array}$ & 0.99 \\
\hline Pre-op Min CS Area & 0.99 & Post-op Min CS Area & 0.99 \\
\hline Pre-op Total Area & 0.99 & Post-op Total Area & 0.99 \\
\hline Pre-op RP Volume & 0.99 & Post-op RP Volume \\
\hline Pre-op OP Volume & Post-op OP Volume & 0.99 \\
\hline
\end{tabular}

\section{Airway Change: All subjects}

When all subjects were grouped together the $\mathrm{p}$-value for the change in all variables was $<0.001$ (Table 2). This indicates that there was a statistically significant change in all variables regardless of the method used to evaluate pre- and post-surgery changes. 
Table 2. Airway Changes for all subjects $(n=28)$.

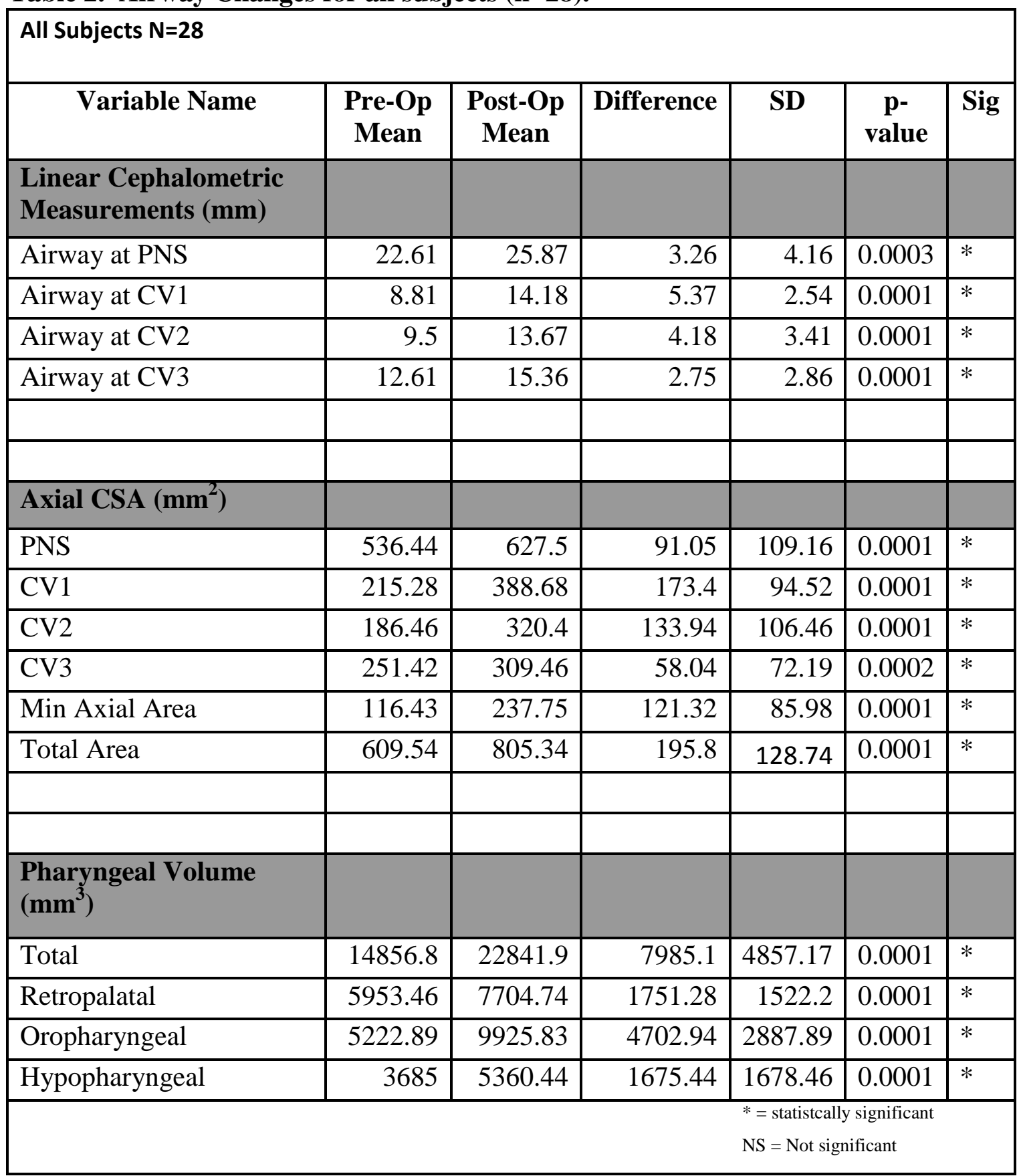




\section{Airway Change in Younger vs. Older Patients.}

The subjects were also divided according to age. Two groups were formed and each group had an $n=14$. One group was identified as the younger age group while the other was called the older age group. The younger age group consisted of individuals whose age ranged from 14-39. The older age group included subjects that were between the ages of 40-80 years. The p-value for both groups in all variables was $<0.05$ (table 3 and 4 ). This indicates that when the subjects were treated with maxillomandibular advancement surgery, there was a statistically significant change in all variables regardless of the age of the patients. 
Table 3. Younger Age Group (n=14).

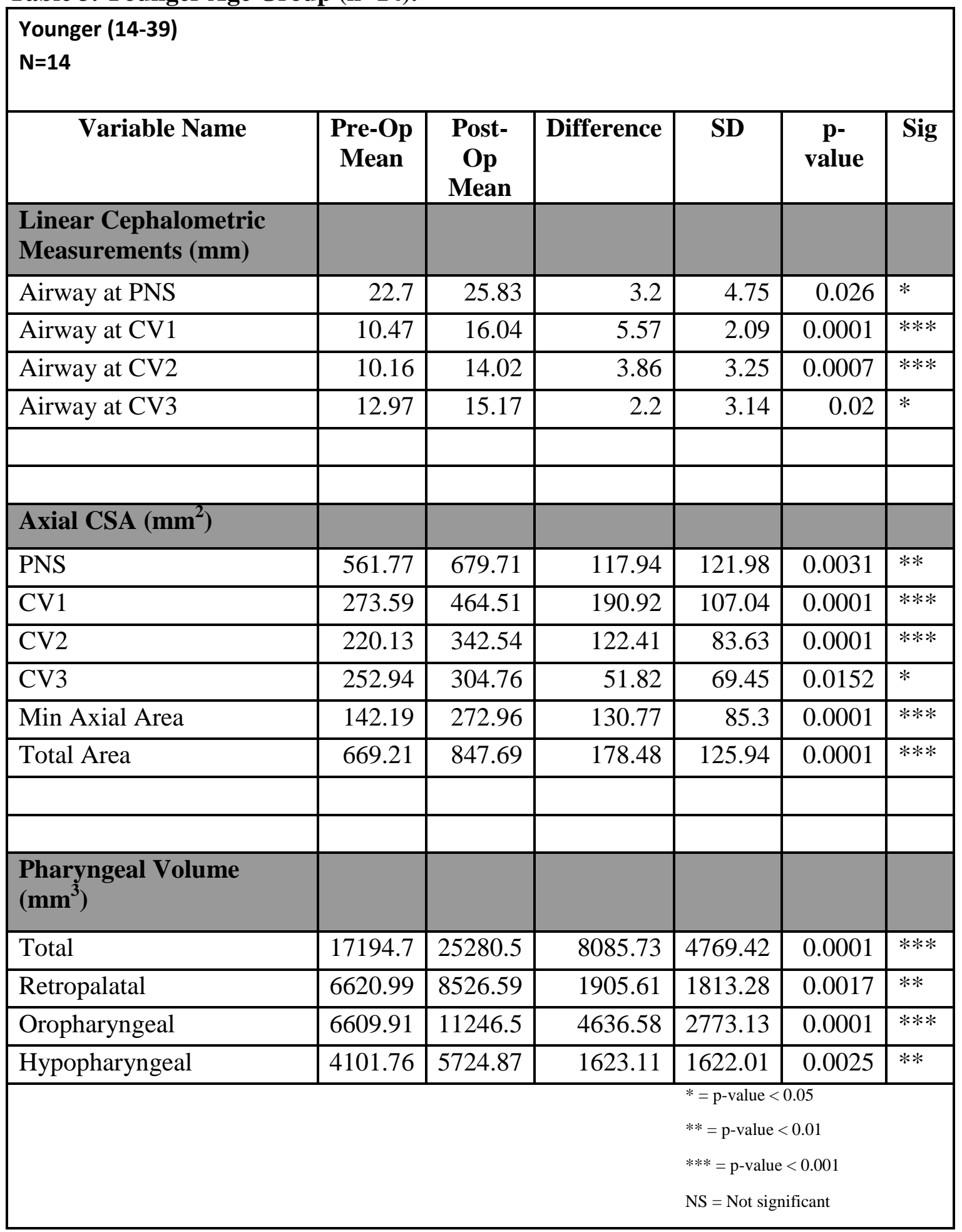


Table 4. Older Age Group (n=14).

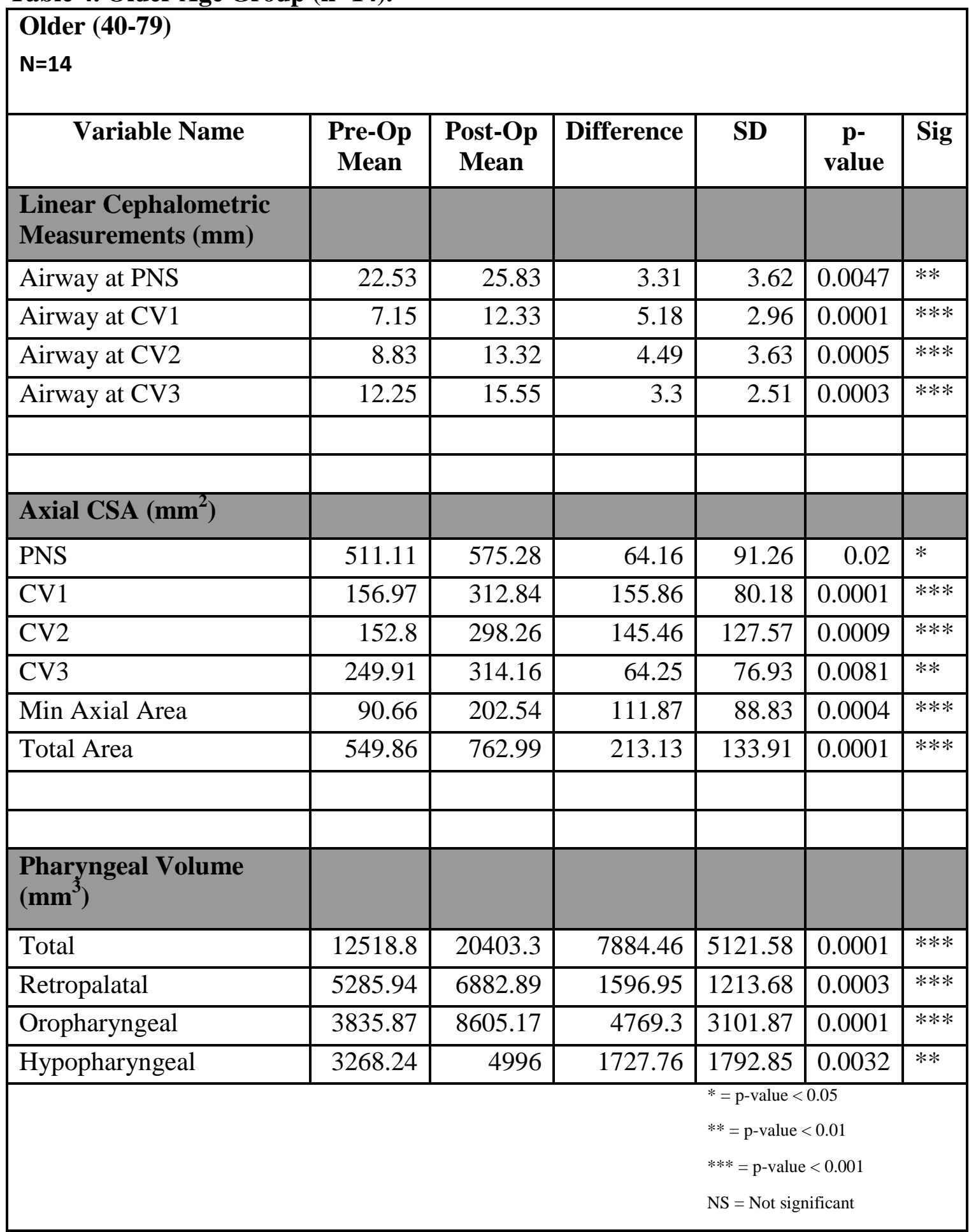




\section{Changes in Airway by MMA with or without Genioplasty}

The subjects were divided into two groups depending on whether or not they received a genioplasty with their MMA surgery. The group that only had MMA surgery was the larger of the two groups with an $n=17$. While the group that did have MMA surgery with a genioplasty had an $n=11$. The $p$-value for both groups in all variables was $<0.05$ (table 5 and 6 ). This indicates that MMA with or without a genioplasty produces a statistically significant change in airway volume, cross-sectional and planar measurements. 
Table 5. Subjects with MMA without Genioplasty.

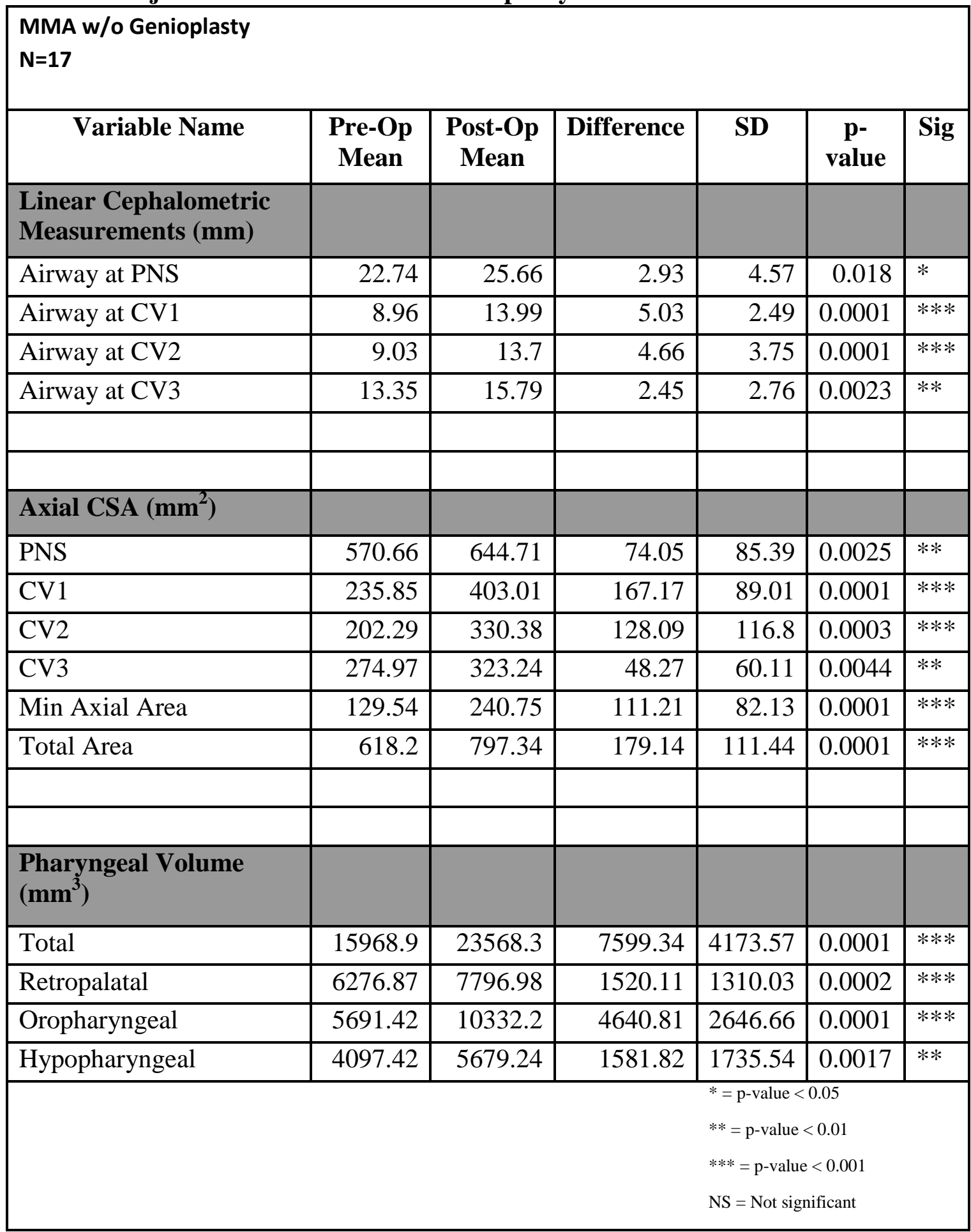


Table 6. Subjects with MMA with Genioplasty

\begin{tabular}{|c|c|c|c|c|c|c|}
\hline \multicolumn{7}{|l|}{$\begin{array}{l}\text { MMA w/ Genioplasty } \\
\mathrm{N}=11\end{array}$} \\
\hline Variable Name & $\begin{array}{c}\text { Pre-Op } \\
\text { Mean }\end{array}$ & $\begin{array}{c}\text { Post- } \\
\text { Op } \\
\text { Mean }\end{array}$ & Difference & SD & $\begin{array}{c}\text { p- } \\
\text { value }\end{array}$ & Sig \\
\hline \multicolumn{7}{|l|}{$\begin{array}{l}\text { Linear Cephalometric } \\
\text { Measurements (mm) }\end{array}$} \\
\hline Airway at PNS & 22.42 & 26.18 & 3.76 & 3.51 & 0.0053 & ** \\
\hline Airway at CV1 & 8.57 & 14.48 & 5.9 & 2.62 & 0.0001 & $* * *$ \\
\hline Airway at CV2 & 10.21 & 13.63 & 3.42 & 2.72 & 0.002 & ** \\
\hline Airway at CV3 & 11.46 & 14.69 & 3.22 & 3.02 & 0.0056 & $* *$ \\
\hline & & & & & & \\
\hline & & & & & & \\
\hline \multicolumn{7}{|l|}{ Axial CSA $\left(\mathrm{mm}^{2}\right)$} \\
\hline PNS & 483.56 & 600.9 & 117.34 & 138.83 & 0.019 & $*$ \\
\hline CV1 & 183.5 & 366.52 & 183.02 & 106.13 & 0.0002 & $* * *$ \\
\hline$\overline{\mathrm{CV} 2}$ & 162.01 & 304.99 & 142.98 & 92.93 & 0.0005 & **** \\
\hline CV3 & 215.03 & 288.16 & 73.13 & 88.71 & 0.021 & $*$ \\
\hline Min Axial Area & 96.17 & 233.12 & 136.95 & 93.39 & 0.0007 & $* * *$ \\
\hline Total Area & 596.14 & 817.7 & 221.55 & 153.95 & 0.0008 & $* * *$ \\
\hline & & & & & & \\
\hline \multicolumn{7}{|l|}{$\begin{array}{l}\text { Pharyngeal Volume } \\
\left(\mathrm{mm}^{3}\right)\end{array}$} \\
\hline Total & 13138 & 21719.2 & 8581.27 & 5931.78 & 0.0007 & $* * *$ \\
\hline Retropalatal & 5453.65 & 7562.19 & 2108.55 & 1810.74 & 0.0031 & $* *$ \\
\hline Oropharyngeal & 4498.79 & 9297.75 & 4798.95 & 3360.6 & 0.0008 & *** \\
\hline Hypopharyngeal & 3047.63 & 4867.74 & 1820.11 & 1658.01 & 0.0045 & $* *$ \\
\hline 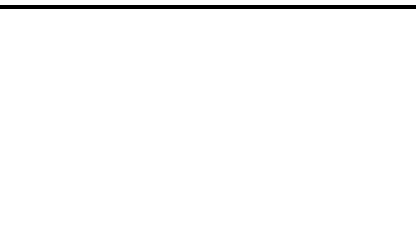 & +2 & 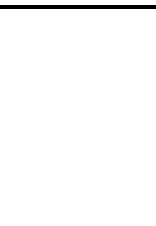 & +2 & $\begin{array}{l}*=\mathrm{p} \text {-value } \\
* *=\mathrm{p} \text {-value } \\
* * *=\mathrm{p} \text {-valu } \\
\mathrm{NS}=\text { Not sig }\end{array}$ & $\begin{array}{l}.05 \\
0.01 \\
<0.001 \\
\text { ficant }\end{array}$ & \\
\hline
\end{tabular}




\section{Change in Airway in Males vs. Females}

The subjects were also divided according to gender. The female group was the larger of the two groups with an $n=19$, while the male group consisted of an $n=9$. The $p$-value for both groups in all variables was $<0.05$, except for except for the cephalometric airway space at the level of CV3 (table 7 and 8). The lack of significance at the level of CV3 on the cephalogram may be due to the small number of males in this study sample. 
Table 7. Male Subjects $(\mathrm{n}=9)$

\begin{tabular}{|c|c|c|c|c|c|c|}
\hline $\begin{array}{l}\text { Male } \\
\mathrm{N}=9\end{array}$ & & & & & & \\
\hline Variable Name & $\begin{array}{c}\text { Pre-Op } \\
\text { Mean }\end{array}$ & $\begin{array}{l}\text { Post- } \\
\text { Op } \\
\text { Mean }\end{array}$ & Difference & SD & $\begin{array}{c}\text { p- } \\
\text { value }\end{array}$ & Sig \\
\hline $\begin{array}{l}\text { Linear Cephalometric } \\
\text { Measurements }(\mathrm{mm})\end{array}$ & & & & & & \\
\hline Airway at PNS & 23.45 & 27.56 & 4.11 & 5.16 & 0.04 & $*$ \\
\hline Airway at CV1 & 9.82 & 16.24 & 6.42 & 2.19 & 0.0001 & **** \\
\hline Airway at CV2 & 10.28 & 14.61 & 4.33 & 2.88 & 0.002 & *** \\
\hline Airway at CV3 & 11.94 & 15.06 & 3.12 & 4.2 & 0.057 & NS \\
\hline & & & & & & \\
\hline Axial CSA $\left(\mathrm{mm}^{2}\right)$ & & & & & & \\
\hline PNS & 574.2 & 700.03 & 125.83 & 118.65 & 0.013 & $*$ \\
\hline CV1 & 275.96 & 504.24 & 228.29 & 84.24 & 0.0001 & *** \\
\hline CV2 & 230.32 & 389.78 & 159.46 & 69.99 & 0.0001 & **** \\
\hline $\mathrm{CV} 3$ & 254.03 & 323.21 & 69.18 & 82.86 & 0.04 & $*$ \\
\hline Min Axial Area & 141.32 & 296.04 & 154.72 & 91.5 & 0.001 & *** \\
\hline Total Area & 731.92 & 962.06 & 230.13 & 128.64 & 0.0007 & $* * *$ \\
\hline & & & & & & \\
\hline $\begin{array}{l}\text { Pharyngeal Volume } \\
\left(\mathrm{mm}^{3}\right)\end{array}$ & & & & & & \\
\hline Total & 18791.8 & 29680 & 10888.2 & 4210.14 & 0.0001 & *** \\
\hline Retropalatal & 7530.56 & 9985.23 & 2454.68 & 1446.39 & 0.0009 & $* * *$ \\
\hline Oropharyngeal & 7013.99 & 13566.8 & 6552.77 & 2750.34 & 0.0001 & $* * *$ \\
\hline Hypopharyngeal & 4279.67 & 6410.53 & 2130.87 & 1775.52 & 0.007 & $* *$ \\
\hline & & & & $\begin{array}{l}*=\mathrm{p} \text {-value } \\
* *=\mathrm{p} \text {-value } \\
* * *=\mathrm{p} \text {-valu } \\
\mathrm{NS}=\text { Not sig }\end{array}$ & $\begin{array}{l}.05 \\
0.01 \\
<0.001 \\
\text { ficant }\end{array}$ & \\
\hline
\end{tabular}


Table 8. Females $(n=19)$

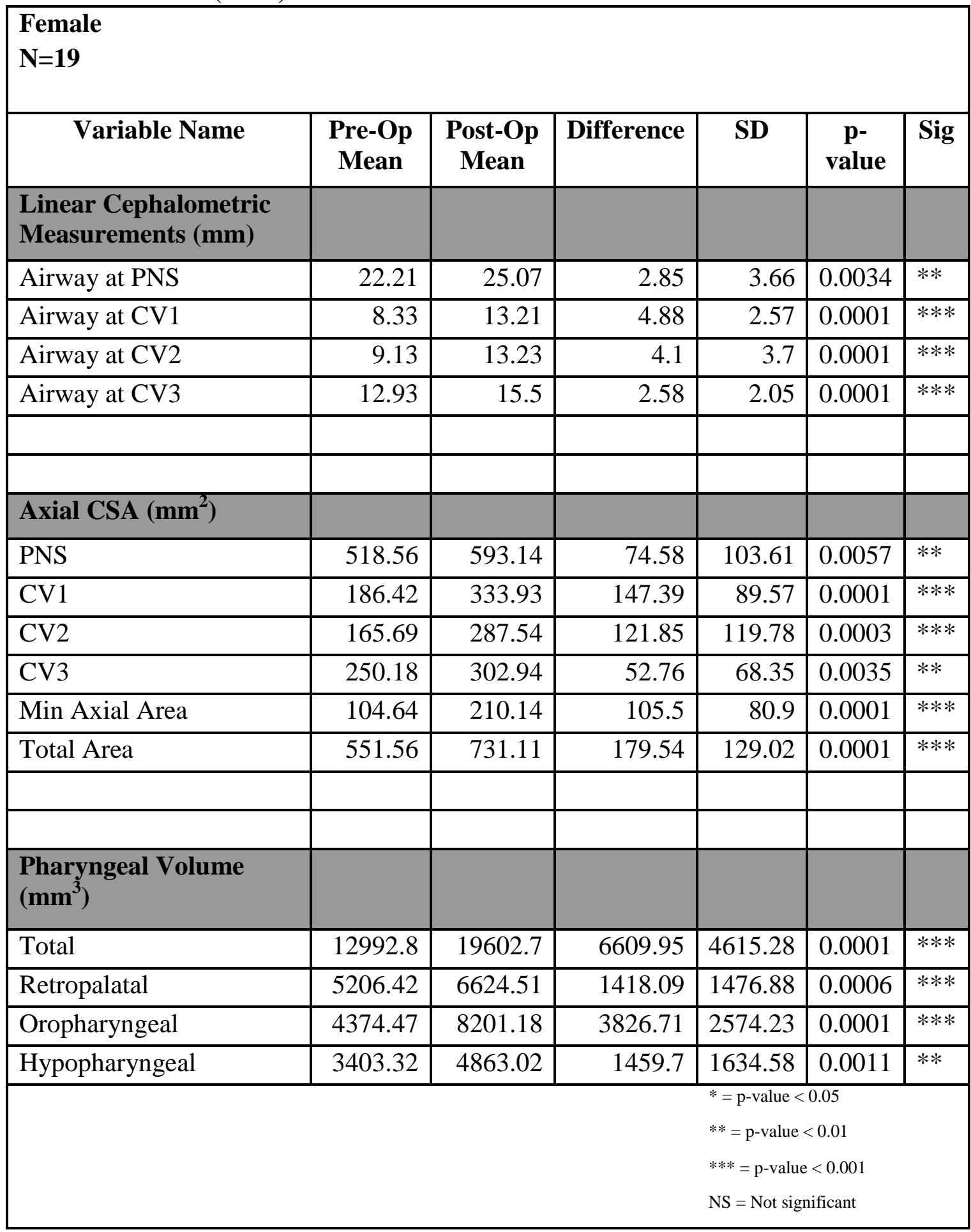




\section{CHAPTER 5: DISCUSSION}

\section{Airway Change: All subjects}

When all subjects were grouped together the $\mathrm{p}$-value for the change in all variables was $<0.001$. This indicates that there was a statistically significant change in all variables regardless of the method used to evaluate pre- and post-surgery changes. It also suggests that although CBCT is a valuable tool to evaluate airway change, cephalometric radiographs can be used to determine whether change in PAS is significant when it pertains to maxillomandibular advancement surgery. In fact, this finding is in agreement with an article by Riley et al., which illustrated a strong correlation between cephalometric PAS measurements and volume ${ }^{49}$.

The results of statistically significant change in airway dimensions at all levels, agrees with recent articles regarding increase in PAS after MMA surgery. The greatest change in the linear and planar measurements was at the level of CV1. The greatest change in volume measurement (excluding total volume) was the oropharyngeal volume. These findings are consistent with Tso et al., which affirm that the oropharyngeal portion is the narrowest region of the airway when a patient is awake and sitting up right ${ }^{67}$.

According to Ogawa et al., the location of the smallest cross-sectional area in patients with OSA was below the occlusal plane in greater than $70 \%$ of the subjects ${ }^{68}$. The current study found that the majority of the patients had their min axial area located below the occlusal plane. This indicates that although not all patients were clinically diagnosed with OSA, they will likely benefit from MMA. 


\section{Airway Change in Younger vs. Older Subjects}

The subjects were also divided according to age. Two groups were formed and each group had an $n=14$. One group was identified as the younger age group while the other was called the older age group. The younger age group consisted of individuals whose age ranged from 14-39. The older age group included subjects that were between the ages of 40-80 years. The $\mathrm{p}$-value for both groups in all variables was $<0.001$. This indicates that when the subjects were treated with maxillomandibular advancement surgery, there was a statistically significant change in all variables regardless of the age of the patients.

As mentioned, statistically significant differences were not seen between either of the age groups. However, the older group consistently had smaller mean pre-op values for all variables that were analyzed. This observation is in agreement with a recent article by Schendel et al., which states that "as individuals grow, the total volume, length, area, and index all increase until age 20 , then remain relatively flat until age 50 , when they all begin to decrease dramatically" ${ }^{\prime 69}$. Schendel also established that most of the total volume decrease was represented by a decrease in the smallest cross-sectional area with age as the airway became smaller which was also seen in this study.

\section{Changes in Airway in Groups with or without Genioplasty}

The subjects were divided into two groups according on whether or not they received a genioplasty with their MMA surgery. The group that only had MMA surgery was the larger of the two groups with an $n=17$. While the group that did have MMA surgery with a genioplasty 
had an $n=11$. The $\mathrm{p}$-value for both groups in all variables was $<0.05$. Therefore there was a significant change in both groups regardless of whether a genioplasty was a part of the surgical procedure. This finding is in concert with an article by Susarla et al., which found that there was no difference in PAS between patients that had MMA alone compare to those that had MMA with a genioplasty ${ }^{70}$.

\section{Change in Airway in Males vs. Females}

The subjects were also divided according to gender. The female group was the larger of the two groups with an $n=19$, while the male group consisted of an $n=9$. The $p$-value for both groups in all variables was $<0.05$, except for except for the cephalometric airway space at the level of CV3. The lack of significance at the level of CV3 on the cephalogram may be due to the small number of males in this study sample.

\section{Limitations of Study}

Limitations of the study included differences in medical history, gender, and ethnicity among the subjects. Orthognathic surgery has been known to have relapse tendency so another limitation of the study was that there was not long-term follow-up data to assess the long-term stability of the surgical treatment. Although CBCT is a tremendous tool in evaluating airway parameters, it does have limitations which include:

1) It is a static evaluation of a dynamic structure

2) Airway dimensions have been shown to change depending on the stage of the breathing 
3) Scans were taken in an upright position. The airway volume has been demonstrated to change when a patient is in a supine position.

\section{CHAPTER 6: SUMMARY AND CONCLUSIONS}

\section{Summary}

The rationale for this study is to gain a better understanding of the alteration in linear, planar and volumetric posterior airway space following double-jaw advancement surgery with a counter-clockwise rotation of the occlusal plane. In addition, this study will investigate whether there is a correlation between 2-dimensional cephalometric and 3-dimensional cross-sectional measurements at specific sites along the airway.

This study was in collaboration with New Hope Orthodontics, which is the private practice of Dr. Mary E. Burns. A total of 28 subjects pre- and post-surgical CBCT scans were evaluated. All of the individuals underwent a maxillomandibular advancement with a counterclockwise rotation of the occlusal plane. All DICOM files were analyzed using Dolphin 3D Imaging 11.5, licensed to West Virginia University Department of Orthodontics. The CBCT volume was used to create right lateral cephalograms which were then used for linear cephalometric measurements. The 3D volume was also utilized to find cross-sectional measurements from axial slices taken from the cone-beam images at specific points: PNS, CV1, CV2 and CV3. Finally, CBCT images were used to find volume measurements at explicit regions along the posterior airway space. Data was analyzed using a matched-pair test. 
Based on results discussed in Chapter IV, the following null hypotheses were rejected:

1. There is no difference in total airway volume pre- and post- MMA surgery.

2. There is no difference in airway volume pre- and post-MMA surgery in the following areas:

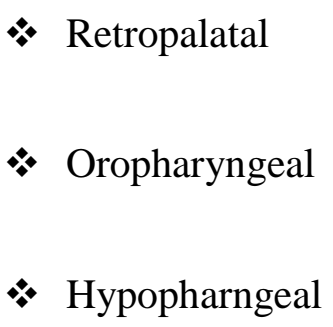

3. There is no significant difference in cross-sectional area pre- and post MMA surgery at the following levels

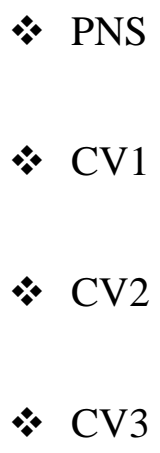

4. There is no correlation between cephalometric linear measurements and 3dimensional cross-sectional measurements

* The maxillomandibular advancement procedure with or without genioplasty illustrated great increases in posterior airway space in both 2-dimensional and 3-dimensional analyses.

* However, more information was available in regards to site of airway obstruction when utilizing the $3 \mathrm{D}$ data in comparison to $2 \mathrm{D}$. 
Therefore, the null hypothesis regarding no correlation in 3D vs. 2D analysis was rejected.

\section{Conclusions}

Maxillomandibular advancement surgery with or without genioplasty illustrated great increases in posterior airway space in both 2-dimensional and 3-dimensional analyses. However, more information was available in regards to site of airway obstruction when utilizing the 3D data in comparison to 2D. Patients with obstructive sleep apnea should be presented with the option of MMA surgery as a treatment option if CPAP is not tolerated.

\section{CHAPTER 7: RECOMMENDATIONS FOR FUTURE RESEARCH}

With the rate of obesity continuing to rise in the United States, OSA is a syndrome that is only going to increase with its prevalence. Possible areas of research could include long-term follow data of the current study. This would help determine the stability of the skeletal movements. Another possible study could evaluate airway length and cross-sectional lateral and anteroposterior measurements pre- and post-surgery. This would help further identify the segment of the airway that increases the most after MMA surgery. In addition this will aid to determine which group of individuals will benefit the most dependent on where their region of most constriction occurs. 


\section{REFERENCES}

1. Goodday RH, Percious DS, Morrison AD, Robertson CG. Obstructive sleep apnea syndrome: Diagnosis and management. J Can Dent Assoc. 2001;67(11):652-658.

2. Li KK. Maxillomandibular advancement for obstructive sleep apnea. J Oral Maxillofac Surg. 2011;69(3):687-694. doi: 10.1016/j.joms.2010.09.014.

3. Abad VC, Guilleminault C. Treatment options for obstructive sleep apnea. Curr Treat Options Neurol. 2009;11(5):358-367.

4. Conley RS, Legan HL. Correction of severe obstructive sleep apnea with bimaxillary transverse distraction osteogenesis and maxillomandibular advancement. Am J Orthod Dentofacial Orthop. 2006;129(2):283-292. doi: 10.1016/j.ajodo.2005.11.029.

5. Barrera JE, Powell NB, Riley RW. Facial skeletal surgery in the management of adult obstructive sleep apnea syndrome. Clin Plast Surg. 2007;34(3):565-573. doi: 10.1016/j.cps.2007.04.010.

6. Brevi BC, Toma L, Pau M, Sesenna E. Counterclockwise rotation of the occlusal plane in the treatment of obstructive sleep apnea syndrome. Journal of Oral and Maxillofacial Surgery. 2011;69(3):917-923. doi: http://dx.doi.org.www.libproxy.wvu.edu/10.1016/j.joms.2010.06.189.

7. Foltan R, Sedy J. The influence of orthognathic surgery on upper airway function is still unknown. Oral Surg Oral Med Oral Pathol Oral Radiol Endod. 2011;111(1):3; author reply 3-4. doi: 10.1016/j.tripleo.2010.09.077.

8. Gilon Y, Raskin S, Heymans O, Poirrier R. Surgical management of maxillomandibular advancement in sleep apnea patients: Specific technical considerations. Int J Adult Orthodon Orthognath Surg. 2001;16(4):305-314. 
9. Goodday R. Diagnosis, treatment planning, and surgical correction of obstructive sleep apnea. J Oral Maxillofac Surg. 2009;67(10):2183-2196. doi: 10.1016/j.joms.2009.03.035.

10. Schendel S, Powell N, Jacobson R. Maxillary, mandibular, and chin advancement: Treatment planning based on airway anatomy in obstructive sleep apnea. J Oral Maxillofac Surg. 2011;69(3):663676. doi: 10.1016/j.joms.2010.11.010.

11. Won CH, Li KK, Guilleminault C. Surgical treatment of obstructive sleep apnea: Upper airway and maxillomandibular surgery. Proc Am Thorac Soc. 2008;5(2):193-199. doi: 10.1513/pats.200708-121MG.

12. Ho ML, Brass SD. Obstructive sleep apnea. Neurol Int. 2011;3(3):e15. doi: 10.4081/ni.2011.e15.

13. Young T, Evans L, Finn L, Palta M. Estimation of the clinically diagnosed proportion of sleep apnea syndrome in middle-aged men and women. Sleep. 1997;20(9):705-706.

14. Conley RS. Evidence for dental and dental specialty treatment of obstructive sleep apnoea. part 1: The adult OSA patient and part 2: The paediatric and adolescent patient. J Oral Rehabil. 2011;38(2):136-156. doi: 10.1111/j.1365-2842.2010.02136.x; 10.1111/j.1365-2842.2010.02136.x.

15. Cutler MJ, Hamdan AL, Hamdan MH, Ramaswamy K, Smith ML. Sleep apnea: From the nose to the heart. J Am Board Fam Pract. 2002;15(2):128-141.

16. Susarla SM, Thomas RJ, Abramson ZR, Kaban LB. Biomechanics of the upper airway: Changing concepts in the pathogenesis of obstructive sleep apnea. Int J Oral Maxillofac Surg. 2010;39(12):11491159. doi: 10.1016/j.ijom.2010.09.007.

17. Aboudara C, Nielsen I, Huang JC, Maki K, Miller AJ, Hatcher D. Comparison of airway space with conventional lateral headfilms and 3-dimensional reconstruction from cone-beam computed tomography. Am J Orthod Dentofacial Orthop. 2009;135(4):468-479. doi: 10.1016/j.ajodo.2007.04.043. 
18. Sears CR, Miller AJ, Chang MK, Huang JC, Lee JS. Comparison of pharyngeal airway changes on plain radiography and cone-beam computed tomography after orthognathic surgery. J Oral Maxillofac Surg. 2011;69(11):e385-94. doi: 10.1016/j.joms.2011.03.015.

19. Ghoneima A, Kula K. Accuracy and reliability of cone-beam computed tomography for airway volume analysis. Eur J Orthod. 2011. doi: 10.1093/ejo/cjr099.

20. Stratemann S, Huang JC, Maki K, Hatcher D, Miller AJ. Three-dimensional analysis of the airway with cone-beam computed tomography. Am J Orthod Dentofacial Orthop. 2011;140(5):607-615. doi: 10.1016/j.ajodo.2010.12.019.

21. Li HY, Chen NH, Wang CR, Shu YH, Wang PC. Use of 3-dimensional computed tomography scan to evaluate upper airway patency for patients undergoing sleep-disordered breathing surgery. Otolaryngol Head Neck Surg. 2003;129(4):336-342.

22. Abramson Z, Susarla SM, Lawler M, Bouchard C, Troulis M, Kaban LB. Three-dimensional computed tomographic airway analysis of patients with obstructive sleep apnea treated by maxillomandibular advancement. Journal of Oral and Maxillofacial Surgery. 2011;69(3):677-686. doi: http://dx.doi.org.www.libproxy.wvu.edu/10.1016/j.joms.2010.11.037.

23. El AS, El H, Palomo JM, Baur DA. A 3-dimensional airway analysis of an obstructive sleep apnea surgical correction with cone beam computed tomography. J Oral Maxillofac Surg. 2011;69(9):24242436. doi: 10.1016/j.joms.2010.11.046.

24. Sonego C, Bobrowski Â, Chagas Junior O, Torriani M. Aesthetic and functional implications following rotation of the maxillomandibular complex in orthognathic surgery: A systematic review. Int J Oral Maxillofac Surg. 2014;43(1):40-45.

25. de Souza Carvalho A, Magro Filho O, Garcia Junior I, Araujo P, Nogueira R. Cephalometric and 
three-dimensional assessment of superior posterior airway space after maxillomandibular advancement. Int J Oral Maxillofac Surg. 2012;41(9):1102-1111.

26. Lye KW. Effect of orthognathic surgery on the posterior airway space (PAS). Ann Acad Med Singapore. 2008;37(8):677-682.

27. Mattos CT, Vilani GN, Sant'Anna EF, Ruellas AC, Maia LC. Effects of orthognathic surgery on oropharyngeal airway: A meta-analysis. Int J Oral Maxillofac Surg. 2011;40(12):1347-1356. doi: 10.1016/j.ijom.2011.06.020.

28. Holty JC, Guilleminault C. Maxillomandibular advancement for the treatment of obstructive sleep apnea: A systematic review and meta-analysis. Sleep medicine reviews. 2010;14(5):287-297.

29. Pirklbauer K, Russmueller G, Stiebellehner L, et al. Maxillomandibular advancement for treatment of obstructive sleep apnea syndrome: A systematic review. Journal of Oral and Maxillofacial Surgery. 2011;69(6):e165-e176.

30. Prinsell JR. Maxillomandibular advancement surgery in a site-specific treatment approach for obstructive sleep apnea in 50 consecutive patients. CHEST Journal. 1999;116(6):1519-1529.

31. Mehra P, Downie M, Pita MC, Wolford LM. Pharyngeal airway space changes after counterclockwise rotation of the maxillomandibular complex. Am J Orthod Dentofacial Orthop. 2001;120(2):154-159. doi: 10.1067/mod.2001.114647.

32. Reyneke J, Bryant R, Suuronen R, Becker P. Postoperative skeletal stability following clockwise and counter-clockwise rotation of the maxillomandibular complex compared to conventional orthognathic treatment. British Journal of Oral and Maxillofacial Surgery. 2007;45(1):56-64.

33. Fairburn SC, Waite PD, Vilos G, et al. Three-dimensional changes in upper airways of patients with 
obstructive sleep apnea following maxillomandibular advancement. J Oral Maxillofac Surg. 2007;65(1):6-12. doi: 10.1016/j.joms.2005.11.119.

34. Lin CH, Liao YF, Chen NH, Lo LJ, Chen YR. Three-dimensional computed tomography in obstructive sleep apneics treated by maxillomandibular advancement. Laryngoscope. 2011;121(6):13361347. doi: 10.1002/lary.21813; 10.1002/lary.21813.

35. http://www.nhlbi.nih.gov/health/public/sleep/yg_slp.htm Web site.

36. Bryan Keropian D. New single-arch sleep appliance therapy. DentistryToday.com Web site. http://www.dentistrytoday.com/dental-medicine/dental-sleep-medicine/975-new-single-arch-sleepappliance-therapy. Published 30 September 2009. Updated 2009. Accessed 2/10, 2013.

37. Ahrens A, McGrath C, Hagg U. A systematic review of the efficacy of oral appliance design in the management of obstructive sleep apnoea. Eur J Orthod. 2011;33(3):318-324. doi: 10.1093/ejo/cjq079; 10.1093/ejo/cjq079.

38. McNamara Jr JA. A method of cephalometric evaluation. Am J Orthod. 1984;86(6):449-469.

39. Güven O, Saraçoglu U. Changes in pharyngeal airway space and hyoid bone positions after body ostectomies and sagittal split ramus osteotomies. J Craniofac Surg. 2005;16(1):23-30.

40. Hochban W, Schürmann R, Brandenburg U. Mandibular setback for surgical correction of mandibular hyperplasia—does it provoke sleep-related breathing disorders? Int J Oral Maxillofac Surg. 1996;25(5):333-338.

41. Hwang S, Chung CJ, Choi Y, Huh J, Kim K. Changes of hyoid, tongue and pharyngeal airway after mandibular setback surgery by intraoral vertical ramus osteotomy. Angle Orthod. 2010;80(2):302-308.

42. Hasebe D, Kobayashi T, Hasegawa M, et al. Changes in oropharyngeal airway and respiratory 
function during sleep after orthognathic surgery in patients with mandibular prognathism. Int J Oral Maxillofac Surg. 2011;40(6):584-592. doi: 10.1016/j.ijom.2011.01.011.

43. Becker OE, Avelar RL, Göelzer JG, Dolzan AdN, Haas Júnior OL, De Oliveira RB. Pharyngeal airway changes in class III patients treated with double jaw orthognathic surgery - maxillary advancement and mandibular setback. Journal of Oral and Maxillofacial Surgery. 2012;70(11):e639e647.

44. Park SB, Kim YI, Son WS, Hwang DS, Cho BH. Cone-beam computed tomography evaluation of short- and long-term airway change and stability after orthognathic surgery in patients with class III skeletal deformities: Bimaxillary surgery and mandibular setback surgery. Int J Oral Maxillofac Surg. 2012;41(1):87-93. doi: 10.1016/j.ijom.2011.09.008.

45. Park JW, Kim NK, Kim JW, Kim MJ, Chang YI. Volumetric, planar, and linear analyses of pharyngeal airway change on computed tomography and cephalometry after mandibular setback surgery. Am J Orthod Dentofacial Orthop. 2010;138(3):292-299. doi: 10.1016/j.ajodo.2009.10.036.

46. Achilleos S, Krogstad O, Lyberg T. Surgical mandibular advancement and changes in uvuloglossopharyngeal morphology and head posture: A short- and long-term cephalometric study in males. Eur J Orthod. 2000;22(4):367-381.

47. Eggensperger N, Smolka K, Johner A, Rahal A, Thüer U, lizuka T. Long-term changes of hyoid bone and pharyngeal airway size following advancement of the mandible. Oral Surgery, Oral Medicine, Oral Pathology, Oral Radiology, and Endodontology. 2005;99(4):404-410.

48. El AS, El H, Palomo JM, Baur DA. A 3-dimensional airway analysis of an obstructive sleep apnea surgical correction with cone beam computed tomography. Journal of Oral and Maxillofacial Surgery. 2011;69(9):2424-2436. 
49. Riley RW, Powell NB, Li KK, Troell RJ, Guilleminault C. Surgery and obstructive sleep apnea: Long-term clinical outcomes. Otolaryngol Head Neck Surg. 2000;122(3):415-421. doi: S0194599800195014 [pii].

50. Bettega G, Pepin J, Veale D, Deschaux C, Raphael B, Levy P. Obstructive sleep apnea syndrome: Fifty-one consecutive patients treated by maxillofacial surgery. American journal of respiratory and critical care medicine. 2000;162(2):641-649.

51. Prinsell JR. Maxillomandibular advancement surgery for obstructive sleep apnea syndrome. J Am Dent Assoc. 2002;133(11):1489-97; quiz 1539-40.

52. James Louis P, Waite PD, Brinks Austin R. Long-term skeletal stability after rigid fixation of le fort I osteotomies with advancements. Int J Oral Maxillofac Surg. 1993;22(2):82-86.

53. Nimkarn Y, Miles PG, Waite PD. Maxillomandibular advancement surgery in obstructive sleep apnea syndrome patients: Long-term surgical stability. Journal of oral and maxillofacial surgery. 1995;53(12):1414-1418.

54. Guijarro-Martinez R, Swennen GR. Cone-beam computerized tomography imaging and analysis of the upper airway: A systematic review of the literature. Int J Oral Maxillofac Surg. 2011;40(11):12271237. doi: 10.1016/j.ijom.2011.06.017.

55. Choi W. Dental computer tomography. . Updated 20102013.

56. Aboudara C, Hatcher D, Nielsen I, Miller A. A three-dimensional evaluation of the upper airway in adolescents. Orthodontics \& craniofacial research. 2003;6(s1):173-175.

57. Moshiri M, Scarfe WC, Hilgers ML, Scheetz JP, Silveira AM, Farman AG. Accuracy of linear measurements from imaging plate and lateral cephalometric images derived from cone-beam computed 
tomography. American Journal of Orthodontics and Dentofacial Orthopedics. 2007;132(4):550-560.

58. Periago DR, Scarfe WC, Moshiri M, Scheetz JP, Silveira AM, Farman AG. Linear accuracy and reliability of cone beam CT derived 3-dimensional images constructed using an orthodontic volumetric rendering program. Angle Orthod. 2008;78(3):387-395. doi: 10.2319/122106-52.1.

59. Kau CH, Richmond S, Palomo JM, Hans MG. Three-dimensional cone beam computerized tomography in orthodontics. J Orthod. 2005;32(4):282-293. doi: 32/4/282 [pii].

60. Schulze D, Heiland M, Thurmann H, Adam G. Radiation exposure during midfacial imaging using 4and 16-slice computed tomography, cone beam computed tomography systems and conventional radiography. Dentomaxillofac Radiol. 2004;33(2):83-86. doi: 10.1259/dmfr/28403350 [doi].

61. Frederiksen NL. X rays: What is the risk? Tex Dent J. 1995;112(2):68-72.

62. Kiefer H, Lambrecht JT, Roth J. Dose exposure from analog and digital full mouth radiography and panoramic radiography. Schweiz Monatsschr Zahnmed. 2004;114(7):687-693.

63. Lenza MG, Lenza MM, Dalstra M, Melsen B, Cattaneo PM. An analysis of different approaches to the assessment of upper airway morphology: A CBCT study. Orthod Craniofac Res. 2010;13(2):96-105. doi: 10.1111/j.1601-6343.2010.01482.x.

64. Hajeer MY, Millett DT, Ayoub AF, Siebert JP. Applications of 3D imaging in orthodontics: Part I. $J$ Orthod. 2004;31(1):62-70.

65. Hernandez-Alfaro F, Guijarro-Martinez R, Mareque-Bueno J. Effect of mono- and bimaxillary advancement on pharyngeal airway volume: Cone-beam computed tomography evaluation. J Oral Maxillofac Surg. 2011;69(11):e395-400. doi: 10.1016/j.joms.2011.02.138.

66. Goncalves JR, Cassano DS, Wolford LM, Santos-Pinto A, Marquez IM. Postsurgical stability of 
counterclockwise maxillomandibular advancement surgery: Affect of articular disc repositioning. J Oral Maxillofac Surg. 2008;66(4):724-738. doi: 10.1016/j.joms.2007.11.007.

67. Tso HH, Lee JS, Huang JC, Maki K, Hatcher D, Miller AJ. Evaluation of the human airway using cone-beam computerized tomography. Oral Surgery, Oral Medicine, Oral Pathology, Oral Radiology, and Endodontology. 2009;108(5):768-776. doi: http://dx.doi.org/10.1016/j.tripleo.2009.05.026.

68. Ogawa T, Enciso R, Shintaku WH, Clark GT. Evaluation of cross-section airway configuration of obstructive sleep apnea. Oral Surgery, Oral Medicine, Oral Pathology, Oral Radiology, and Endodontology. 2007;103(1):102-108.

69. Schendel SA, Jacobson R, Khalessi S. Airway growth and development: A computerized 3dimensional analysis. J Oral Maxillofac Surg. 2012. doi: 10.1016/j.joms.2011.10.013.

70. Susarla SM, Abramson ZR, Dodson TB, Kaban LB. Upper airway length decreases after maxillomandibular advancement in patients with obstructive sleep apnea. J Oral Maxillofac Surg. 2011;69(11):2872-2878. doi: 10.1016/j.joms.2011.01.005. 


\section{APPENDIX}




\section{W. WestVirginiaUniversity.}

Office of Research Integrity and Compliance

\section{Acknowledgement Letter Not Human Subject Research NHSR}

To

From

Approval Period

Subject

Protocol Tracking

Title
Peter Ngan

WVU Office of Research Integrity and Compliance

01/23/2014 Expiration Date 01/22/2019

Not Human Subject Research Acknowledgment

1401168620

Total Airway Volume Comparison Pre- and Post-Orthognathic Surgery

Thank you for your submission to the West Virginia University Institutional Review Board IRB.

It has been determined that your project does not meet the definition of human subject research for the following reasons

- In order to be considered human subject research, individually identifiable private information must be obtained or used in the research. If there is no individually identifiable private information involved, the project is not human subject research and does not require being submitted to the Office of Research Integrity \& Compliance. Private information must be individually identifiable (i.e., the identity of the subject is or may be readily ascertained by the investigator or someone else associated with the information) in order to constitute research involving human subjects.

If you have any questions, please contact the IRB at 3042937073.

Thank you.

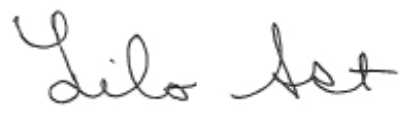

Board Designee Lilo Ast

Letter Sent By Lilo Ast on 01/23/2014 at 20:08:45-05:00 


\section{CURRICULUM VITAE}

Deepa Vyas was born in Ahmedbad, India and moved to Texas when she was 1 1/2 years old. She is the daughter of Rekha and Kirit Vyas and sister to Pranav and Charul Vyas. Deepa was raised in Friendswood, Texas, a suburb of Houston. While attending the University of Texas at Austin, she obtained a degree in Biochemistry. After graduating college, she participated in the national service program AmeriCorps for 6 months.

She then attended dental school at Boston University School of Dental Medicine and received a D.M.D. in 2011. While at Boston University, Deepa was involved in the following organizations: DMD 2011 Class Officer, American Student Dental Association (ASDA), Student National Dental Association, Hispanic Dental Association, Alpha Omega Fraternity, ASDA Big Brothers, Big Sisters, American Association of Women Dentists, Student Research Group, and Orthodontic Study Club. In addition to being actively involved in her community she was also on the dean's list every semester and graduated the top of her class. Following dental school Deepa started her orthodontic residency, under the guidance of Chairman Dr. Peter Ngan, in July 2011 and will graduate April 2014 with an M.S. degree and a certificate in Orthodontics. 